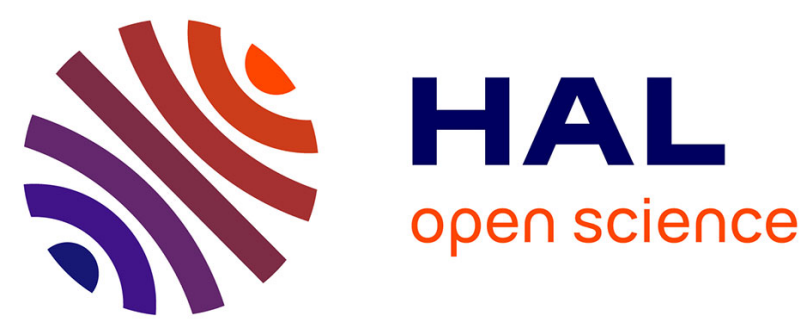

\title{
A typology of split conjunction
}

\author{
Enrique L. Palancar
}

\section{To cite this version:}

Enrique L. Palancar. A typology of split conjunction. Linguistic Typology, 2012, 16 (2), pp.265-320. 10.1515/lity-2012-0009 . hal-01493916

\section{HAL Id: hal-01493916 https://hal.science/hal-01493916}

Submitted on 22 Mar 2017

HAL is a multi-disciplinary open access archive for the deposit and dissemination of scientific research documents, whether they are published or not. The documents may come from teaching and research institutions in France or abroad, or from public or private research centers.
L'archive ouverte pluridisciplinaire HAL, est destinée au dépôt et à la diffusion de documents scientifiques de niveau recherche, publiés ou non, émanant des établissements d'enseignement et de recherche français ou étrangers, des laboratoires publics ou privés. 


\title{
A typology of split conjunction
}

\author{
Enrique L. Palancar \\ CNRS, SeDyL-CELIA (UMR8202) \\ Surrey Morphology Group, University of Surrey
}

2012

Linguistic Typology 16, 265-320

\begin{abstract}
In this paper, I study instances of noun phrase conjunction where the conjoined noun phrase is subject and the referents of the conjuncts are human, of the type 'John and Mary are having lunch'. More specifically, I study different, possible splits that occur in such structures, which involve the disruption of the phrasal continuity of the conjuncts, resulting in structures roughly equivalent to 'they are having lunchwith Mary' and 'John are having lunch with Mary'. I claim that such splits are allowed by the inherent asymmetries of conjunctional structures, and I see them as functionally motivated by a play of prominence of the conjuncts involved. In the paper, I advance a typology of such splits in three subtypes: (i) splits by elision, where the conjuncts form a constituent but their phrasal contiguity is disrupted because the more salient conjunct is elided due to its topicality; (ii) splits by extraction, where the salient conjunct is given even more prominence by being extracted to a topical position thus breaking the continuity of the conjuncts; and (iii) splits by integration, where the role of the less salient conjunct is upgraded by means of dual or plural agreement on the verb. The constructions equally involve standard coordinative structures of the type 'Mary and I' as well as other noncoordinative types such as inclusory conjunctionamong others.
\end{abstract}

Key words.Conjunction, coordination, comitatives, split conjunction, split coordination.

\section{Introduction.}

The study of coordinating constructions has been a subject of continuous interest for linguistic typology because of theirgreat diversity in the world's languages both language internally and cross-linguistically. It is for this reason that the literature is vast, and I will mention just a few works here. The various studies in Haspelmath (2004a), together with the comprehensive surveys in Haspelmath $(2004 \mathrm{~b}, 2007)$ are foundational in this respect. More specifically for the purposes of the present study, the typology of noun phrase (henceforth NP) conjunction in the various works by Stassen $(2000,2001,2003)$ has been fundamental. Similarly, the studies in Corbett $(1991,2000,2006)$ have become a landmark for the general agreement properties of conjoined NPs and their cross-linguistic peculiarities.

As novel linguistic data from lesser known languages expands our awareness of the existence of previously unknown possibilities in natural language, the enterprise of linguistic typology continuously faces the need to expand and accommodate this new knowledge. This paper is intended as a contribution to the expansion of a typology of conjunctional constructions, more specifically in the area of NP conjunction, precisely in the light of aspects of conjoiningconstructions of a few languages which have not yet 
gained the attention of the typological literature and which pose interesting challenges for a taxonomy of conjunction.

In particular, I study here the different possibilities of a phenomenon I call 'split conjunction'. Split conjunction comprises various types of conjunctional structures which share two properties: (i) the fact of having two discontinuous conjuncts in a clause and (ii) a clausal predicate that shows resolved agreement with both of the conjuncts. The discontinuity of the conjuncts may occur at a superficial level or at a deeper level in the syntax of clausal structure.In this connection, I briefly revisit the so-called 'split inclusory pronoun constructions'in Lichtenberk (2000)-also called 'asymmetrical conjunction' in Bril (2010, 2011, in press) - and propose to include them as a subtype of split conjunction. However, the paper especially aims to present more severe cases of split conjunction that involve structures like the one shown in (1), from Santa Ana Otomi, an Oto-Manguean language of Mexico, where the two NP conjuncts appear in different positions in the clause, while the verb indexes both as subject via resolved agreement.

\section{(1) Santa Ana Otomi (Oto-Manguean, Oto-Pamean; Selene Hernández, p.c) \\ [ma mbe] nuya baP=n-tsi-hme=wi [a \\ 1POSS mother today 3.PST.TRANSLOC=ANTIP-ingest-tortilla=DU DEF.SG priest \\ 'My mother ate today with the priest.' \\ 'My mother and the priest ate(together) today.'}

Conjoined NPs may appear in all levels of clausal structure, and may involve conjuncts ranking differently in the animacy hierarchy and bearing different feature values (typically gender, number, and case). Because of this, for convenience, I have restricted the object of my study to instances of conjunctional strategies where the conjuncts rank highest in the animacy hierarchy (i.e., they are humans) and where the resulting conjoined NP functions as the subject of the clause (i.e., I exclude cases where the conjoined NP is object or possessor). Beyond convenience, the restriction of the object of study is also justified on the theoretical level, because the range of the conjunctional strategies involving the splits that I present in this paper are often restricted only to subject conjoined NPs which involve humans acting together as a team in the completion of the event. $^{1}$

The paper is structured as follows. First, in the next section I give an overview of what I believe are the principal parts in the state of the art regarding NP conjunction. This involves the relation between comitative and coordinative constructions, as well as other types of conjunctional strategies such as inclusory conjunction, summative conjunction and associative conjunction. I intend this introduction to create a common background in a coherent and systematic way to be able to introduce split conjunction, which I do in $\S 3$. In $\S 3$, I define split conjunction and I propose that it comes in three disguises, as it were, namely in the form of splits by elision, splits by extraction and splits by integration. I study these splits independently in subsequent sections, but advance areas of intersection in the end of the paper in the conclusion section.

\section{An overview of noun phrase conjunction.}

Although NP conjunction involves other types of conjunctional strategies (see §2.2), the phenomenon is commonly illustrated at a first instance by examples of NP coordination as

1 In this paper, I do not make a distinction between conjoined NPs involving full NP conjuncts like 'the man and the woman' and other which involve pronominal conjuncts like 'the man and I' or 'you and I'. Whether the subtleties of the distribution of conjunctional splits are due to the lexical nature of the conjuncts (i.e. nouns vs. pronouns) remains an open question. 
in (2) from English, where the NP John and the NP Mary are conjoined into a larger NP structure John and Mary, by means of the relator or coordinator and.

\section{(2) [John and Mary] were leaving for the station}

The conjoining structure in English in (2) is further treated as syndetic because there is an overt relator (i.e. and) to link the two NPs. Example (3) illustratesan instance of NPconjunction by means of asyndesis, where the second conjunct is syntactically juxtaposed to the first one. ${ }^{2}$

(3) Nyangumarta (Australian, Pama-Nyungan; Sharp 2004: 315 apud Sadler and Nordlinger 2006: 340)

pala-nga ngatu jarri-nya-pinti-ngi, mima-nikinyi-yi puluku, that-LOC stationary INCH-NM-ASS-LOC wait.for-IMPFV-3PL.SUB 3DU.DAT

[kujarra kangkuru-jirri waraja yalapara]

two kangaroo-DU one goanna

'And there, on the finishing line, the two kangaroos and one goanna waited for thosetwo.'

Both (2) and (3) are instances of NP coordination, ${ }^{3}$ which in this paper, adopting Singer's (2001a: 81) proposal, I define as a group of NPs in which elements of equal rank are conjoined together into a larger group, which is prototypically a group of two. ${ }^{4}$

On the other hand, the semantic relation between the linked NPs in (2) is of 'conjunction', which is characterized in Stassen (2003: 763-64) as in (4):

(4) "A sentence contains a case of NP conjunction

a. if it describes a single occurrence of an event (action, state, process, etc.)

b. and if this event is predicated simultaneously of two (and no more) participant referents, which are conceived of as separate individuals."

2 An asyndetic conjoined NP is often framed within a special intonational phrase that cues the hearer to interpret a conjoined interpretation for the syntax. In example (i) of Jamsay, a NigerCongo language, the final syllabic nucleus of each conjunct is prolonged with a slowly falling pitch to which Heath (2008: 266) refers as 'dying-quail intonation', indicated by the sign $\div$.

(i) Jamsay (Niger-Congo, Dogon; Heath 2008: 270)

$m i \div \tilde{n} E /-m \div$

$1 \mathrm{SG}$ woman-PL

'me and the women.'

3 According to Stassen $(2001,2003)$, asyndesis is much less frequent than syndesis as a coordinative structure, but it becomes quite common in other types of conjoining structures such as inclusory conjunction (see $\$ 2.2 .1$ ).

4 Different definitions of coordination abound. For example, Haspelmath (2007: 1) proposes that "the term coordination refers to syntactic constructions in which two or more units of the same type are combined into a larger unit and still have the same semantic relations with other surrounding elements.", while Zwart (2005: 233) prefers a more formal definition as "a constituent $x$ is a noun phrase coordination iff $x$ contains two or more noun phrases realizing a single argument or grammatical relation". In principle all these definitions cover prototypical examples of the type in (2). 
Notice, however, that the definition in (4) also accounts for the semantics of the typical comitative structure in (5), where only the participant John is subject, while Mary is encoded as an adjunct oblique.

\section{(5) [John] was leaving for the station [with Mary]}

Both (2) and (5) are instances of (4) because for either of them there is an available interpretation that (a) the act of leaving occurred only once and that (b) this act was predicated simultaneously of both John and Mary. However it is useful to bear in mind that while (2) and (5) are both seen as conjoining structures, only the structure in (2) is an instance of a coordination. Besides, the two structures are not perfectly synonymous because they have different semantic entailments if the state of affairs predicated is an action event, instead of a motion event, as for example in (6) and (7).

(6) [John and Mary] are having lunch

(7) [John] is having lunch [with Mary]

In the coordinative structure in (6), the content of (4a) is an implicature that can be cancelled. For example, while the default interpretation of both (6) and (7) is that John and Mary had lunch and that they had it simultaneously, in the same place and together, a possible alternative interpretation of (6) is that John and Mary indeed had the meal but the act of eating could have happened in different places (and of course not together). In contrast, in the comitative structure of (7) the content of (4a) is an entailment.

Following Stassen's (2003) proposal, I view the coordinative structure in (2) and (6) and the comitative structure in (5) and (7) as two opposing extremes in a grammatical continuum toencode conjunctional semantics. The defining features characterizing each strategy as a prototype are given in (8), (Stassen 2003: 780).

\section{Coordinative strategy}

a. NPs have same structural rank

b. Unique coordinative particle

c. NPs form a constituent

d. Plural/dual agreement on the verb

\section{Comitative strategy}

NPs differ in structural rank

Unique comitative marker

NPs do not form a constituent

Singular agreement on the verb

Of the four features in (8), feature (a) refers to the dimension of the symmetry/asymmetry of the relation between the conjuncts involved. In the prototype, the coordinative structure is symmetrical (i.e., it portrays the conjuncts as bearing a symmetrical relation to each other), while the comitative structure is asymmetrical because the two NPs differ in structural rank. In (5) and (7), for example, the referents of the NPs hold a semantic relation of accompaniment, but only one (John) is topical and subject (when established, it is often elidedor encoded with an anaphoric pronoun), while the other participant (Mary) is less prominent and often carries new information, although it can also serve as a secondary topic for the following discourse. The topical NP conjunct in the comitative structure is treated by Stolz (2001) as the 'focal-participant', while the nontopical NP conjunct is called the 'associate participant'. ${ }^{5}$ Besides, the asymmetry between the two conjuncts is one of control, as pointed out in Haspelmath (2004b: 15-16). Here, of the two participants, the topical subject is the one in full control of the action and is the only one to be held accountable for it.

5 Also, according to Stolz et al. (2006: 17), the NPs play different semantic roles: the focalparticipant is ACCOMPANEE whilethe associate participant is the COMPANION. 


\subsection{The origin of comitative coordinators.}

On the other hand, it is well-known that comitative markers are often used as coordinators across languages, and the works by Stassen $(2001,2003,2011)$ have shown that comitative coordination is typologically common. My understanding of Stassen's proposal is that this situation is functionally motivated by an increase in the degree of symmetry between the conjuncts. ${ }^{6}$ For convenience, I illustrate this dynamism here in Hausa. In this light, the comitative construction in (9) would represent a first stage for the dynamics, a sort of a point of departure.

(9) Hausa (Chadic, Afro-Asiatic; Abdoulaye 2004: 182)

[Feemi] yaa tàfi İkko [dà ùba-n-shi]

Femi 3SG.M.PFV go Lagos with father-of-3SG.M

'Femi went to Lagos with his father.'

On this comitative structure, the following two principles are implemented:

- Principle 1: The relation between two participants is more symmetrical if they are conceived of as a unit in the form of a group (typically of two members).

- Principle 2: A group is efficiently perceived as a unit if its members are close to each other, that is, if they are together.

The principles can be first realized by making the phrases encoding the two conjuncts appear contiguously in the clause. This is achieved by moving the comitative conjunct closer to the subject conjunct, as in (10).

(10) Hausa (Chadic, Afro-Asiatic)

[Feemi $] \quad[$ dà ùba-n-shì $] \quad y a a \quad$ tàfi İkko

Femi with father-of-3SG.M 3.SG.M.PFV go Lagos

'Femi with his father went to Lagos.'

But the stage in (10) is highly unstable in both SVOX and VSOX languages because of the prominent informative position of the comitative phrase, and hence it is rarely attested and is likely to be produced only in elicitation. ${ }^{7}$ Instead, the emerging structure commonly leads to a sudden reanalysis of the syntactic boundaries of the phrases realizing the two conjuncts into a unified constituent. The semantic role of this newly emerged constituent is interpreted following another principle.

- Principle 3. A group is more symmetrical if its members have an equal degree of participation, that is, if they act together or have the same semantic role.

6 A further way to increase the symmetry between the conjuncts is to mark them equally; this was first proposed by Haiman (1985a: 84) for Hua (Papuan). Stassen (2003: 793) found some other instances in Nubian (Nilo-Saharan, East Sudanic), Cuzco Quechua (Andean) and Kobon (Papuan, East Highlands).

7 For VOSX languages, this stage is not available because of the surface contiguity of S and the comitative phrase. 
Such a principle is then realized by making the verb agree with the two conjuncts via semantic agreement involving number resolution (e.g. plural/dual), as in (11). ${ }^{8}$ The new structure gives rise to a comitative coordinator. ${ }^{9}$

(11) Hausa (Chadic, Afro-Asiatic; Abdoulaye 2004: 183)

$\begin{array}{llll}{[\text { Feemì dà } \quad \grave{a} b a-n-s h i]} & \text { sun } & \text { tàfi İkko } \\ \text { Femi and/with father-of-3SG.M } & \text { 3.PL.PFV } & \text { go Lagos } \\ \text { 'Femi and his father went to Lagos.' } & & \end{array}$

In this conception, which I take to be representative of the general view shared by many language typologists, the coordinative strategy is viewed as a beacon of symmetry when the two conjunctional strategies in (2) and (5) or (6) and (7) are compared in the encoding of conjunctional semantics. ${ }^{10}$

However, most would also agree that the symmetry of coordination is a canonical ideal rather than the common situation, because in most instances of coordination one of the conjuncts is usually more prominent than the other. In my view, the underlying asymmetry of coordinative structures is inherited from the conceptual asymmetry characterizing the essence and core of conjunction itself. ${ }^{11}$ In this regard, adopting Smith's (2003) terminology, I call 'primary conjunct' the prominent conjunct of a conjunctional structure, whatever its subtype, whether coordinative or other. Likewise, the second next prominent conjunct will be referred to as the 'secondary conjunct'. ${ }^{12}$

In this respect, the asymmetry of NP coordination can be seen in various phenomena; the most relevant one being word order. Here the order of the conjuncts is far

8 In resolved agreement or agreement via resolution, the appropriate feature values must be computed, (see Corbett 2006: 168 ff, 238 ff).

9 In languages where verbs are not targets of subject number agreement, the constructions may remain ambiguous (see Amfo 2010 for a discussion on Akan).

${ }^{10}$ The concept of symmetry used here is equivalent to "conceptual symmetry" as defined by Haiman (1985a: 73-74) where two elements A and B are said to be symmetrical with respect to a relationship $r$ in at least one of the following two situations: (a) whenever $\{\mathrm{A} r \mathrm{~B}\}$ and $\{\mathrm{B} r$ A $\}$ are both true. This is the prototypical case of actors involved in reciprocal relations like in (ii); or (b) whenever $\{\mathrm{A} \mathrm{r} \mathrm{C}\}$ and $\{\mathrm{B} \mathrm{r} \mathrm{C}\}$ are both true. This happens when the two actors are portrayed as performing the same action, as in (ii).

\section{(ii) [Max and Harry $]$ hit each other}

11 As extensively discussed in Haiman (1985b), the asymmetry of coordination rests on the inherent linearity of the linguistic sign, because in the phonological string when saying $A a n d B$, $A$ is necessarily perceived before $B$, and word order is invested here, as elsewhere in the grammar, with cognitive symbolism.

12 In formal theories of syntax such as Principles and Parameters theory and Minimalism, the common view of the structure of noun phrase coordination since the works by Johannessen (1996, 1998), Kayne (1994), and Radford (1993) among others, is to understand coordination as bearing the typical asymmetrical structure of a single-headed $\mathrm{X}$-bar phrase called ConjP, where the coordinator is the head, and the primary and the secondary conjuncts occupy the specifier and the complement positions, respectively. Coordination is viewed as inherently asymmetric because these theories take it that grammar is not capable of generating symmetric structures (Cormack and Smith 2005). Other theories do not assume this structure, for example Lexical Functional Grammar (Dalrymple and Kaplan 2000, Bresnan 2000), or Head-driven structure Phrase Structure Grammar (Pollard and Sag 1994). For reasons why the ConjP analysis is not accepted in these frameworks see Borsley (2005). 
from being random, but responds to a number of hierarchies comprehensively characterized in Allan (1987), including degree of familiarity of the conjuncts (e.g. the primary conjunct comes first and is more familiar), topic vs. comment, universal sequencing conventions, etc. Asymmetry is also revealed when the order is fixed, because the lack of syntactic freedom points to an unequal ranking, as in well-known examples from English, such as those in (12), (see Wälchli 2005 for an extended discussion). ${ }^{13}$

(12) a. mum and dad/?dad and mum

b. brothers and sisters/*sisters and brothers

c. ladies and gentlemen/*gentlemen and ladies

Other phenomena revealing asymmetry between coordinated NPs is further seen when the verb agrees with only one of the conjuncts, commonly the nearest to the verb (Corbett 2006: 168-70, 180, etc.; Benmamoun et al. 2009; etc); when only one of the conjuncts serves as locus for case marking (Johannessen 1998; Smith 2003 among others) $;^{14}$ when only the primary conjunct has binding properties (e.g. John $n_{\mathrm{i}}$ and his $s_{\mathrm{i}}$ mother, but his $\mathrm{s}_{\mathrm{i}}$ mother and $J o h n_{\mathrm{j}}$ ); or when the comitative coordinator still keeps government properties from being an apposition (for example in Russian, where the comitative coordinator $s$ governs instrumental case, Feldman 2002: 41).

There are other types of conjunctional strategies identified in the literature which are more asymmetrical than coordination, and I will only revisit them briefly in the next section. These include conjunctional constructions by means of inclusory and summative pronouns as well as associate plurals. While coordination remains the least asymmetrical of conjunctional structures, the asymmetries present in all such constructions both feed and allow the natural occurrence of the conjunctional splits I study in more detail in $\S 3$. This is why it is important to review them here using the same approach.

\subsection{Other conjunctional strategies.}

2.2.1. Inclusory pronoun constructions. In this section, I revisit briefly other types of conjunctional strategies found across languages. Among these the most common is the type that Haspelmath (2007) calls 'inclusory conjunction', also called 'inclusory pronoun construction' in Lichtenberk (2000) and formerly known as the 'plural pronoun construction' in Schwartz (1985, 1988a) and Aissen (1989). Variants of this construction occur widely across languages in all continents, while they are especially characteristic of many Austronesian (Bril 2004, 2010, 2011, in press), Australian (Singer 2001a, 2001b) and Afro-Asiatic languages.

13 Similarly, the politeness rule that dictates that conjuncts should be aligned against the person hierarchy $1<2<3$, e.g. my friend and I/me instead of me and my friend or Spanish Juan, Antonio y yo ('John, Anthony and I') instead of yo, Juan y Antonio, also responds to asymmetry. Whether this is a learned rule rather than an acquired one is irrelevant for our purposes, because what is important is that it is based on the perception that the order of the conjuncts is meaningful: placing the higher pronoun in the hierarchy in the last position is regarded as a sign of humility, and showing humility is a well-known strategy to encode politeness. In some cases, it grammaticalizes so that the option $I / m e$ and my friend is no longer as frequent as my friend and $\mathrm{I} / \mathrm{me}$, and for some even ungrammatical.

14 Outside coordination, a similar mismatch in case marking is also found in the inclusory conjunction of Tagalog. Here the inclusory pronoun, being the primary conjunct, may appear in an unmarked case, while the secondary conjunct (the subset included in the pronoun) remains case marked. For more details see Bril (2011: 250). 
Inclusory conjunction is used to conjoin a pronoun, which is formally and semantically treated as the primary conjunct, plus the NP (or another pronoun ranking lower in the person hierarchy) of the secondary conjunct. The primary conjunct defines a superset in which the reference of the secondary conjunct is included as a subset, and for this reason it is called the 'inclusory pronoun'. Two typical examples are given in (13).Here, as elsewhere in the paper, I have underlined the secondary conjunct.

(13) a. Nêlêmwa (Eastern Oceanic, New Caledonia; Bril, in press: 213)

[yaman ma $\underline{\text { Polie }}]$

1DU.EXCL.FR CONJ Polie

'Polie and I.'

b. Tzotzil (Mayan; Aissen 1989: 524)

[vo?oxuk xchi?uk i j-tzebe]

you.PL and/with DEF 1POSS-daughter

'You (sg) and my daughter.'

For the purposes of this paper, two aspects of inclusory conjunction are relevant. One is its inherent asymmetrical nature; the other verb agreement. I will discuss them succinctly here.

Inclusory conjunction is more asymmetrical than coordination. The asymmetry lies in the fact that the inclusory pronoun clearly functions as the head of the phrase, while the secondary conjunct is perhaps better treated as its specifier. As we will see in $\S 3.1$, the split that is common in inclusory conjunction lies at the heart of this asymmetry because the head inclusory pronoun is often elided by default. In the construction, the inclusory pronoun refers to a superset that includes the reference of the secondary conjunct by indexing what Singer (2001b) calls the 'central member' of the conjunction. This central member corresponds to the focal participant in comitative semantics (i.e., the first person in I with you). The included subset is the associate participant (i.e., the second person in $I$ with you). In this respect, Bril (2004: 509-510) has shown that a situation involving the first and the second person is naturally construed as [we.two.INCL\& you], but also as [we.two.INCL\& I] for very specific circumstances where the speaker lacks control of the action. $^{15}$

The use of an inclusory construction to convey conjunctional semantics imposes its own characteristic semantic frame upon the situation. On the one hand, inclusory constructions appear to be equally translatable with a coordinative strategy ('I and the man') or with a comitative strategy ('I with the man'). In reality, they represent a third semantic type, lying in the midst of these two strategies, which is not easily translatable in English or for that matter in other languages lacking the type. ${ }^{16}$ In this connection, Bril (2004, 2010, in press) has pointed out that the structures are commonly used to express a nuance of accompaniment that profiles a close relation between the participants involved. This is the case to such an extent, that in most languages the construction can only be used with humans, as for example, in Hungarian and in Polish (Moravcsik p.c. apud Schwartz

15 The example in question was said by a blind speaker who used to go fishing with the hearer on a regular basis and was thus guided by him. Here the speaker naturally portrayed himself as being less in control of the situation.

16 To compensate for this, authors often add a literal translation of the sort 'we two includingthe man'. 
1988b: 242), or only with animates, as in Southern Zapotec (Beam 2006) and in Nêlêmwa (Bril 2004). ${ }^{17}$

Another important feature that becomes relevant with split cases is to keep in mind that when the inclusory phrase is subject, ${ }^{18}$ the verb agrees with the inclusory pronoun. This is clearly shown in Hausa in (14).

(14) Hausa (Chadic, Afro-Asiatic; Abdoulaye 2004: 166)

[muu dà shii] mun jee kàasuwaa

1PL and/with 3SG.M 1PL.PFV go market

'He and me, we went to the market.'

Apart from inclusory conjunction, two other minor types remain: summative pronouns and associative plurals. I introduce each succinctly next.

2.2.2. Summative pronoun constructions. In some languages, the conjuncts can also be conjoined by means ofanother construction that involves a head pronoun that computes the number values of each of the conjuncts put together, as illustrated in (15). I call this construction 'summative conjunction' inspired by Bril (2010), who calls it a 'summation pronoun strategy'. ${ }^{19}$ The asymmetry of summative conjunction lies in the fact that both conjuncts are headed by the summative pronoun. ${ }^{20}$ The examples in (15) further illustrate the fact that the verb agrees with the summative pronoun. ${ }^{21}$

a. Manam (Austronesian, Oceanic; Lichtenberk 1983: 430, apud Bril 2010: 362)

\begin{tabular}{|c|c|c|c|}
\hline$[$ nau & tora-gu & Réru] & 7i-réba-ru \\
\hline 1SG.FR & older.brother-1SG & 1DU.EXCL.FR & 1DU.EXCL-sail-DU \\
\hline
\end{tabular}

17 As Bril (2010) points out, the existence of the phrasal inclusory construction correlates with the avoidance of conjunction of pronouns in many languages; not a definitional feature of the construction, but a natural consequence of its existence for expressive purposes. These are banned in Nêlêmwa, but are to be found in Taqabaqita (p.8), where the use of and-coordination is restricted so same level salience. At times they use different means, asyndesis for the inclusory construction and syndesis for coordination, like in Ajië (Oceanic) (Bril 2010: 6). Notice that the use of an explicit conjunction commonly separates the conceptual unity of the inclusory group.

18 In some languages, mostly Oceanic and Chadic, the inclusory conjunction can also be used in phrases that work as objects and as possessives.

19 Aikhenvald (2008) prefers the name 'argument elaboration construction', whereas Haspelmath (2007) treats it as a subtype of inclusory conjunction on the basis that the superset of the summative pronoun in a way 'includes' the reference of the subsets of the individual conjuncts.

20 The ranking of the conjuncts is as symmetrical as they can get in standard coordinative constructions where their order is motivated by hierarchical principles.

${ }^{21}$ Summative conjunction can become an inclusory construction if the primary conjunct (the one that selects the person value of the head summative pronoun) is elided. This is shown in (iii), if compared with (15b).

(iii) Mapudungun (Isolate; Smeets 2008: 139)

[fey iñchiu] nütram-ka-y-u

he we.DU converstation-FACT-IND-1DU

'He and I talked.' 
b. Mapudungun (Isolate; Smeets 2008: 138)

[iñché eymi iñchiu] $\frac{i-y-u}{\text { you we.DU }}$ eat-IND-1DU
I 'You (sg) and I ate.'

Alternatively to summative pronouns, in the Southern Zapotec languages of Mexico, one finds summative conjunction by means of quantifier verbs (Beam 2006), as illustrated in (16). This type will become relevant for the discussion about splits in \$3.2. further below.

(16) Quiegolani Zapotec (Oto-Manguean; Black 2000: 260)

r-oo men nisgaal [y-rup men Biki]

HAB-drink 3 soda POT-be.two 3 Virginia

'She and Virginia drink soda pop.'

(lit. 'They drink soda being two she and Virginia.')

2.2.3. Associative conjunction. Finally, there is another type of conjunction that involves an NP encoding the superset by virtue of being marked with an associative plural. This NP includes the reference of the secondary conjunct as its subset. The construction is not widespread, being limited already to languages with associative plurals. Haspelmath (2007: 34) acknowledges having found only one example of it, which is given in (17a) from Margi. ${ }^{22}$ The example in $(17 \mathrm{~b})$ is from Central Alaskan Yup'ik, whose relevance is discussed in Corbett (2000: 107-110). ${ }^{23}$

(17) a. Margi (Afro-Asiatic, Chadic; Hoffmann 1963: 57 apud Haspelmath 2007: 34)

[Kàmbə 『ràwázhá'-yàr àgá $\quad \underline{\text { màlà ga } \square n d a ̀] ~}$

Kamburawazha-ASS.PL and/with wife of.him

'Kamburawazha and his wife.'

b. Central Alaskan Yup'ik (Eskimo Aleut; Corbett and Mithun 1996: 12)

[Cuna-nku-k arnaq=llu] ayag-tu-k

Chuna-ASS-DU woman=too go-IND-3.DU

'Chuna and the woman left.'

22 The example, with a slightly different orthography, appears in Vassilieva (2005: 2). As for published material, the example first appears in Moravcsik (2003: 494), but it has errors, including the glossing of -yàr as a plural marker, not as an associative plural. Moravcsik acknowledges in footnote 26 that she was made aware of this structure by Martin Haspelmath and Maria Vassilieva. Another mention of the same example appears in Bhat (2004: 92). All go back to a manuscript by Haspelmath dated 2000, which later became Haspelmath (2007).

23 Associative conjunction is the mirror-image of a special inclusory conjunction construction found in a number of Australian languages where the secondary conjunct is explicitly marked as being a subset of the larger set indexed by the inclusory pronoun (Singer 2001b). Such a construction is illustrated in Yidi) in (iv).

(iv) Yidi) (Australian, Pamanyungan; Dixon 1977: 178)

[ $\mathrm{na}$ d $\mathrm{i}$ bu/a:-ba] galin

1.NON.SG woman-ONE.OF.GROUP go.PRES

'A woman and I (and some others) are going.' 
In this section, we have seen various encoding possibilities for conjunctional semantics. These include coordinative, inclusory, summative, associative and comitative conjunction.The schematic syntax of these strategies is given for convenience in (18). In this notation, the conjunct (nominal or pronominal) that serves as the primary conjunct in each of the structuresis indicated by the number ' 1 '; the secondary conjunct by the number ' 2 '. The ampersand represents a relator. In syndetic inclusory, summative and associative strategies the relator used is commonly a comitative one, but I have placed it in between parentheses to include asyndetic instances as well, which are more common in these types of conjoining structures than in coordination.

(18) Different conjunctional strategies

a. Coordinative: $\left[\mathrm{NP}_{1} \& \mathrm{NP}_{2}\right]_{\text {SUB }} \quad \mathrm{V}+\mathrm{DU} / \mathrm{PL}$

b. Inclusory: $\quad\left[\mathrm{PRO}_{1}+\mathrm{DU} / \mathrm{PL}\left[(\& \mathrm{COMIT}) \mathrm{NP}_{2}\right]\right]_{\mathrm{SUB}} \quad \mathrm{V}+\mathrm{DU} / \mathrm{PL}$

c. Summative: [ PRO/V+DU/PL[NP 1 (\&COMIT) $\left.\left.\mathrm{NP}_{2}\right]\right]_{\mathrm{SUB}} \mathrm{V}+\mathrm{DU} / \mathrm{PL}$

d. Associative: [ $\left.\mathrm{NP}_{1}+\mathrm{ASS}\left[(\& \mathrm{COMIT}) \mathrm{NP}_{2}\right]\right]_{\mathrm{suB}} \quad \mathrm{V}+\mathrm{DU} / \mathrm{PL}$

e. Comitative: $\left[\mathrm{NP}_{1}\right]_{\mathrm{suB}} \quad \mathrm{V}+\mathrm{SG} \quad$ [COMIT $\left.\mathrm{NP}_{2}\right]$

To close this section it is sensible to remind ourselves that languages often have more than one conjunctional strategy at hand. When this happens, the distribution and usage of the alternatives is often conditioned by the semantics, ${ }^{24}$ but also by discourse functions. ${ }^{25}$ All the strategies schematized in (18), except comitative conjunction, typically involve conjuncts in contiguous phrases, as seen in the examples so far, but such a contiguity can be broken, crucially resulting in a phenomenon I call 'split conjunction'. In the following sections, I study this phenomenon in detail. In the next section, I start with a definition, and then I present its various types.

\section{Split noun phrase conjunction.}

I use the term 'split noun phrase conjunction', abbreviated simply as 'split conjunction', to refer to a conjunctional structure involving two NPs (nominal or pronominal) which has the following two properties: (i) the conjuncts are discontinuous in the clause, and (ii) the clausal predicate, commonly a verb, shows resolved agreement with both of the conjuncts treating them equally as subject. None of the strategies presented so far, summarized in (18) above, qualify as instances of split conjunction. The comitative structure fulfills (i) but not (ii). The rest of the strategies (i.e., coordinative, inclusory, summative and associative) fulfill (ii), but not (i).

Split conjunction is a phenomenon that responds to the inherent asymmetry existing between the two conjuncts as it is perceived by speakers. In this respect, speakers play with the prominence of the conjuncts in the way they chose to present them in the description of the event,while they still portray them equally as co-actors through the

24 A common exemplary case is illustrated by Tariana (Arawakan), which employs asyndetic coordination for inanimates but comitative coordination for humans (Aikhenvald 2003). The distribution may equally respond to the type of conjuncts involved. For example, among other constructions, Nêlêmwa (Austronesian, Oceanic) has a syndetic coordinative strategy to conjoin full NPs, but restricts the use of the inclusory conjunction in (13a) to animate conjuncts involving a pronoun (Bril 2004). Likewise, Manam (Austronesian, Oceanic) uses summative conjunction when the conjunction involves a pronoun, but comitative coordination when conjoining full NPs (Lichtenberk 1983: 430, apud Bril 2010: 326).

25 For example, according to Aikhenvald (2008) Manambu (Papuan, Sepik) has up to four different strategies to conjoin NPs involving human referents: asyndetic and comitative coordination, inclusory conjunction and summative conjunction. 
resolved agreement in the verb. As a result of this interplay of prominence, we obtain different types or structural manifestations of split conjunction. In other words, the different types of split conjunction revealdifferent possible ways of resolving the conflict of which one of the two co-actors gets the stage, the protagonist or the antagonist. I propose there are three main types of conjunctional splits: 'splits by elision', 'splits by extraction' and 'splits by integration'.

One common way to play with the asymmetry of the conjuncts is by downgrading the role of the primary conjunct. This results in 'split conjunction by elision', which involves both inclusory and coordinative constructions, asI show in the next section. In splits by elision, the secondary conjunct is the only overt constituent in the clause. This split is introduced in $§ 3.1$.

Alternatively, another way to deal with the conflict of prominence between the conjuncts is to bluntly present them as asymmetrical. This is commonly achieved by making the two conjuncts appear in different positions in the clause. However, to resolve the conflict, speakers may decide to reduce the asymmetry by presenting them equally as co-actors in the event. This alternative leads to at least two other types of splits. In 'split conjunction by extraction', presented in $\$ 3.2$, the relevance of the primary conjunct is enhanced by extracting its phrase to a prominent syntactic position in the clause. This split is found in inclusory and summative conjunction, although only rarely. In 'split conjunction by integration', on the other hand, the discontinuity of the conjuncts is there by default, but the role of the secondary conjunct is upgraded from its background by integrating it as a co-actor in the event through the resolved agreement on the verb. This type of split is introduced in \$3.3. Finally, in some languages of the Americas, there are also instances of conjunctional constructions featuring a split by integration which work as independent constructs in the grammar of conjunction. I refer to such cases as 'severe split conjunction' and will be dealt with more extensively in $§ 3.4$.

In principle, split conjunction may involve all types of the conjunctional strategies in (18), but because of its cross-linguistic rarity, we lack evidence that languages with the associative type have developed a split. Consequently, I will not be saying anything else about this type here.

\subsection{Split conjunction by elision.}

The primary conjunct is likely to be the established topic from the previous discourse. If this happens, it may be entirely downgraded by not being overtly expressed. This is possible becausethe verb allows for some type of resolved agreement with all the conjuncts together. ${ }^{26}$ I treat such cases as instances of 'split conjunction by elision', where

${ }^{26}$ In the computation of feature values in resolved agreement, the person value is calculated following the same principles that rule the selection of the inclusory pronoun in inclusory conjunction. Such principles are spelled out in Corbett (2006: 240) as: "If the conjuncts include a first person, agreement will be first person. Otherwise, if the conjuncts include a second person, agreement will be second person. The default situation is that agreement is third person." In coordination, resolved agreement commonly attends to such principles, but there can be exceptions. For example in French, Grevisse and Goose (1993: 1329-1330) report on various (although rare) instances where agreement is resolved with the third person, as in des efforts que faisaient Damien et moi-même 'the efforts Damien and I used to make' (Dhôtel, Je ne suis pas d'ici, p. 40) instead of more canonical des efforts que faisions Damien et moi-même, or mes enfants et moi vous disent mille tendresses 'my children and I send you all our love' (Sand, Correspondance, 20 juillet 1845) instead of mes enfants et moi vous disons mille tendresses. For other cases, agreement with the third person is with the nearest conjunct as in lorsque toi et tes frères ouvraient à Noël leurs paquets de cadeaux somptueux 'when you and your brothers opened your/their packets of sumptuous presents in Christmas' (Simenon, 
the term 'elision' is intended here in a noncommittal manner as a way to refer to the process by which the NP (or a pronoun) of one of the conjuncts is not expressed in surface structure.

The elision of the primary conjunct produces a superficial type of split which is common across languages with inclusory conjunction. The conjunctional constructions bearing this split are currently known in the literature as 'split inclusory pronoun constructions' from Lichtenberk (2000), but they were initially called 'verb-coded coordination' in Schwartz (1988b). As a consequence of the elision, the secondary conjunct is the only conjunct of the whole conjoined NP that surfaces in the clause. A number of illustrative examples are given in (19).
a. Toqabaqita (Austronesian, Oceanic; Lichtenberk 2000: 3)
[doqora-mu] mere ngata
brother-2SG 1DU.EXCL.NONFUT speak
'Your brother and I spoke.'

b. Nêlêmwa (Austronesian, Oceanic; Bril 2004: 508)

io ma tu haga [ma Polie $]$

FUT 1DU.EXCL go.down fish CONJ Polie

'I'll go fishing with Polie' or 'Polie and I will go fishing.'

c. Tzotzil (Mayan, Aissen 1989: 522)
l-i-bat-otikotik
ta ch'ivit
COMPL-1 ABS-go-1PL.EXCL
to market and/with DEF Xun
'I went to the market with Xun.'

d. Hausa (Afro-Asiatic, Chadic; Abdoulaye 2004: 185)
mun jee kàasuwaa [dà $\underline{\text { Abdù }}]$
1PL.PFV go market and/with Abdu
'We went to the market, Abdu and me.'

In these examples where the conjoined NP functions as subject, the secondary conjunct designating the subset is the only conjunct overtly expressed as an NP. The primary conjunct, the inclusory pronoun indexing the superset, is elided because it is topical, although its reference can be recovered from the context and from the agreement index on the verb. The split construction in these examples can be viewed as an instance of syntactic pro-drop, see Aissen (1989) and Corbett (2000: 233). ${ }^{27}$ In this direction,

Mémoires intimes, p.11). In reality, when French native speakers are confronted with made-up examples showing a similar phenomenon such as for example Jean et moi sont arrivés à la gare for Jean et moi sommes arrivés à la gare 'John and I arrived at the station', the consensus is to regard them as ungrammatical. Speakers react to the deviating examples above as slips of the pen. In this respect, Grevisse and Goose (1993: 1329) comment: "il s'agit dans plus d'un cas, il est vrai, de lettres ou d'autres écrits peu élaborés".

${ }^{27}$ In my opinion, the wording used by some authors to describe the agreement pattern in split conjunction by elision is not a fortunate one because it ascribes an inclusory function to the agreement morphology, when this is not entirely necessary. For example Lichtenberk's (2008: 669): "In split inclusory constructions, the inclusory pronominal and the included NP do not form a phrase together. There is no independent inclusory pronoun; rather, the superset is encoded by means of a dependent pronominal." (emphasis mine). The equation is taken a step further in Haspelmath (2007: 34), where the phenomenon is described as "many languages also 
Schwartz (1988b), who sees this phenomenon under the general rubric of 'verb-coded coordination', proposes that allowing pro-drop elsewhere in the grammar is indeed one of the fundamental prerequisites for a language to have this type of split.

The schematic syntax of this split is given in (20). For languages with syndesis, splits by elision are only attested when the relator linking the secondary conjunct to the inclusory pronoun already works as a comitative relator.Split inclusory conjunction is not afully independent construction in the grammar, but an alternative manifestation of the construction where both conjuncts form a contiguous phrase.

(20) Split by elision and inclusory conjunction

contiguous: $\left[\mathrm{PRO}_{1}+\mathrm{DU} / \mathrm{PL}\left[(\text { \&COMIT }) \mathrm{NP}_{2}\right]\right]_{\text {SUB }} \quad \mathrm{V}+\mathrm{DU} / \mathrm{PL}$

split: $\quad\left[\mathbf{1}_{\text {GIVEN.TOP }}+\mathrm{DU} / \mathrm{PL}\left[(\& \text { COMIT }) \mathrm{NP}_{2}\right]\right]_{\mathrm{SUB}} \mathrm{V}+\mathrm{DU} / \mathrm{PL}$

The elided inclusory pronoun can be restored, but when this happens the clause is pragmatically charged, as the overt occurrence of the topical primary conjunct is construed as being emphatic, as in (21). Also, the full phrase may be treated differently in the syntax for information structure purposes. This may be seen in (21c) from Tzotzil, an VOS language where the subject is extracted as external topic by means of the enclitic =?un, or in Hausa in (21d), a SVO language where it is placed in topical position.

(21) a. Toqabaqita (Austronesian, Oceanic; Lichtenberk 2000: 10)

[kamareqa doqora-ku] meki lae ma-i

1DU.EXCL brother-1SG 1DU.EXCL.FUT go DIR-at

'I and my brother will come tomorrow.'

b. Nêlêmwa (Austronesian, Oceanic; Bril 2011: 241)

mo pîila wuung [yamon ma âlô-raamwa eli]

2DU stroll together 2DU.FR CONJ young-woman that.ANPH

'You took a walk, you and that girl.'

c. Tzotzil (Mayan, Aissen 1989: 524)

[li vo?otikotik xchi?uk li Maryan=?un=e] te l-i-kom-otikotik

DEF we.EXCL and/with DEF Maryan=ENC=ENC there COMPL-1 ABS-stay-1PL.EXCL

'Maryan and I stayed there.'

d. Hausa (Afro-Asiatic, Chadic; Abdoulaye 2004: 185)

[muu dà shii] mun jee kàasuwaa

1PL and/with 3SG.M 1PL.PFV go market

'He and me, we went to the market.'

3.1.1. Split coordination by elision. Although splits by elision are typical of inclusory conjunction, they can also be found in coordinative conjunction, although more rarely, as it seems. An example of split coordination by elision is (22) from Chilean Spanish.

(22) Chilean Spanish (Schwartz 1988: 54)

fu-imos a-l cine [con mi madre $]$

went-1PL to-the cinema and/with my mother

'My mother and I went to the cinema.'

have a construction in which the inclusory pronominal element is a clitic pronoun or a coreference marker on the verb." (emphasis mine). 
On the surface, the structure in (22) looks like an instance of the split construction in (19), but in reality Chilean Spanish, like any other dialect of Spanish, lacks an inclusory construction. This is illustrated by the impossibility of the inclusory reading of (23) (cf. example 21d).

(23) [nosotros con mi madre] fu-imos a-l cine we.M and/with my mother went-1PL to-the.M cinema Exclusory reading: 'We and my mother went to the cinema.' Inclusory reading: ' 'I and my mother went to the cinema.'

In this way, the real elided primary conjunct in the split in (22) is the pronoun for the first person singular yo, as illustrated in (24). As in all examples in (21) above, once the primary conjunct is restored, the construction is emphatic, and like in the Hausa example in (21d), the full phrase occurs preverbally as topical subject. ${ }^{28}$

(24) [yo con mi madre] fu-imos a-l cine

I and/with my mother went-1PL to-the cinema

'I and my mother went to the cinema.' (ibid. 64)

Just as in inclusory constructions, the split by elision in coordinative structures is only allowed with comitative relators.For example, in Chilean Spanish, while the genuine coordinator $y$ 'and' would be perfectly possible in the contiguous construction in (24), it cannot be used in the split of (22), as shown by the infelicity of (25), presumably because of the Coordinate Structure Constraint by Ross (1967).

(25) Spanish (infelicitous in all dialects)

*fu-imos a-l cine [y mi madre $]$

went-1PL to-the cinema and my mother

Intended reading: 'My mother and I went to the cinema.'

In this way, the schematic syntax of split coordination by elision is given in (26).

(26) Split by elision and coordination

contiguous: [ $\mathrm{NP}_{1} \&$ COMIT $\left.\mathrm{NP}_{2}\right]_{\text {SUB }} \quad \mathrm{V}+\mathrm{DU} / \mathrm{PL}$

split: $\quad\left[{ }_{1} \quad 1 \text { GIVEN.TOP\&COMIT NP }\right]_{\text {SUB }} \quad \mathrm{V}+\mathrm{DU} / \mathrm{PL}$

Another example of split coordination by elision is found in the Boumaa dialect of Fijian. Consider for instance, the coordinative structure in example (27a), which is emphatic, or (27b), where both Mary and John represent new information.

(27) Boumaa Fijian, (Austronesian, Oceanic, Polynesian; Dixon 1988: 157)

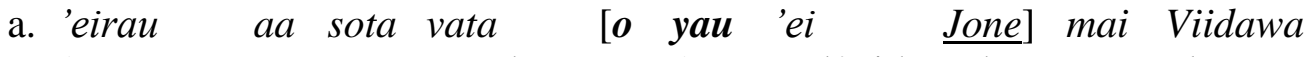

1DU.EXCL PST meet together ART 1SG and/with John at place

'John and I met at Viidawa.'

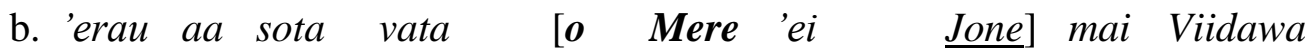

28 Comitative coordination in Spanish has been studied in Camacho (1996) and (2000). In the latter work, Camacho shows that this conjunctional strategy is relegated to subject position only and that it must have a collective interpretation. 
3DU PST meet together ART Mary and/with John at place

'Mary and John met at Viidawa.'

When the primary conjuncts in (27) arethe established topics of the discourse, older speakers have available the split encoding in $(28),{ }^{29}$ while younger speakers prefer the comitative construction in (29), where the verb no longer shows resolved agreement.

(28) a. 'eirau aa sota vata ['ei Jone] mai Viidawa

1DU.EXCL PST meet together and/with John at place

'John and I met at Viidawa.' (ibid. 157)

b. 'erau aa sota vata ['ei Jone] mai Viidawa

3DU PST meet together and/with John at place

'She and John met at Viidawa.' (ibid. 157)

(29) au aa sota vata ['ei Jone] mai Viidawa

1SG PST meet together with John at place

'I met up with John at Viidawa.' (ibid. 159)

3.1.2. The secondary conjunct in splits by elision.Leaving out the primary conjunct may equally serve as a mechanism to increase the narrative salience of the secondary conjunct. An example of this is given in (30a) from Manambu, where the participant Lumawand $\leftrightarrow m$, a chief of a renowned village to the hearers, is presented as a focal protagonist of the scene, yet encoded as the secondary conjunct. Aikhenvald (2008) treats this example as an instance where the inclusory pronoun is left out. Another example with comitative coordination in the same language is given in $(30 \mathrm{~b})$, where the secondary conjunct is presented as an anti-topic.

(30) Manambu (Papuan, Sepik; Aikhenvald 2008)

a. aw a [Lumawad $\leftrightarrow m$ ] $k w a-b r \leftrightarrow-l$

then then Lumawand $\leftrightarrow \mathrm{m}$ stayed-3DU.SUB-3F.SG.BAS

'Then Lumawand $\leftrightarrow \mathrm{m}$ (and the village) stayed.' (141)

b. gra- $k \leftrightarrow$-dana-di $\quad[d \leftrightarrow-k \leftrightarrow \quad$ takwa-wa $]$

cry-FUT-3PL.SUB.VT-3PL.BAS.VT 3M.SG-OBL.3F.SG woman.LK-COMIT

'They all cried, (them) including his wife.' (142)

29 Notice that the predicate vata 'together' in these examples is not a summative pronoun like in $\$ 2.2 .2$ above. The same structure obtains when vata is not used, like in (v), (Dixon 1988: 158).

(v) Boumaa Fijian, (Austronesian, Oceanic, Polynesian; Dixon 1988: 157)

o rau saa sota 'ina ['ei+ $\underline{\text { na }}$ gone.tuuraga

ART 3DU ASP meet PREP+3SG and/with+ART high.chief

a tuuraga.bete $n i \quad$ Faranisee, $o$ Paatere Lorosio]

ART priest ASSOCIATED France ART Father Lorenzo

'They two met there, (Tui Ca'au) and a great chief, a French priest, Father Lorenzo.'

The adverbial predicate vata 'together' is used in (28-29), just like in many other instances, as a semantic indicator that the conjuncts act as a group. For younger speakers, the predicate has become reanalyzed as part of the complex preposition vata 'ei 'with'. 
The latent asymmetry allows for the extraction of the secondary conjunct to a position of external topic (31), ${ }^{30}$ and it can be further questioned (32) or relativized (33). ${ }^{31}$

(31) Boumaa Fijian, (Austronesian, Oceanic, Polynesian; Dixon 1988: 160, my glossing)

$\begin{array}{lllll}{\left[\begin{array}{l}\text { a tuuraga.bete mavaa } \\ \text { ART priest 'eirau na vei-vasa'i vata }\end{array} \text { DEM }\right.} & \text { 1DU.EXCL } & \text { FUT REC-talk together }\end{array}$

'That priest, he and I will talk together.'

(32) Nêlêmwa (Austronesian, Oceanic; Bril 2004: 508)

hli $u \quad$ muuvi $[\mathrm{ma}$ ti $]$ ?

3DU PRF stay CONJ who

'Who did (s)he live with?'

(33) Chilean Spanish ${ }^{32}$

Por esos días también conocí a quien sería mi señora,

by those days also met.1SG.PST ACC.DEF.ANIM who would.be.3sG my wife

un- $a$ hermos-a puertomontin- $a$

a-F beautiful-F person.from.Puerto.Montt-F

[con la que nos casa-mos a fin-es de 2003]...

with the.F REL 1PL.REC marry-1PL(PST) at end-PL of 2003

'In those days I met (the person) who would be my wife, a beautiful woman from

Puerto Montt to whom I got married towards the end of 2003...'

(lit. '...with whom we got married')

But not all languages allow the same syntactic freedom to the phrase of the secondary conjunct. For example, if the comitative phrase in the Hausa example in (34a) is extracted, the resulting structure is no longer an instance of inclusory conjunction, as the plural agreement on the verb is no longer interpreted as targeted by the inclusory pronoun, but by a plural pronoun with a genuine plural reference. This is illustrated in (34b), where the comitative phrase is external topic in the topic fronting construction, and in (34c) where it occurs in a cleft focus structure.

(34) Hausa (Afro-Asiatic, Chadic; Abdoulaye 2004: 186)
a. mun jee kàasuwaa [dà Bàlaa $]$
1PL.PFV go market with Bala

Inclusive reading: 'I went to the market with Bala.'

Exclusive reading: 'We went to the market with Bala.'

\section{b. [là Bàlaa $]$ kàm, mun jee kàasuwaa}

30 The construction in (31) is the most common, but a pronominal copy of the secondary conjunct in the form of 'ei 'ea or kaya 'and/with him' can be left behind in the clause after the predicate vata.

31 The relative clause is based on a structure like porque cuando nos casamos con mi esposa... 'because when my wife and I got married' (Lit 'because when we married my wife') from <http://www.elsolquilmes. com.ar/imprimir.php?n_id= 43097>.

32 From <http://www.elrepuertero.cl/admin/render/noticia/15967>. 
with Bala indeed 1PL.PFV go market

'As for Bala, we did indeed go to the market, he and me.'

c. [dà $\quad \underline{\text { Bàlaa }}]$ nèe mu-kà jee kàasuwaa
with Bala COP 1PL-PFV go market
'It is with Bala that we went to the market.'

In this section, I have presented instances of split conjunction by elision, where the primary conjunct is elided because it is the established topic of the discourse. Alternatively to elision, we also find conjunctional structures where the asymmetry between the conjuncts is maximized by either breaking their contiguity and thus producing a different type of split I call 'split conjunction by extraction'. This is studied in the next section.

\subsection{Split conjunction by extraction.}

Speakers may also want to foreground the role of the primary conjunct in the event, increasing further the inherent asymmetry of conjunction. One way to achieve this is by breaking the contiguity of the conjuncts by placing the primary conjunct in a prominent informative position in the clause. This produces a more severe disruption in the syntax of the clause than in the split cases by elision presented in the previous section, which I call 'split conjunction by extraction'. Splits by extraction produce a double effect. The primary conjunct is clearly presented as the participant who is in control of the action, while the secondary conjunct becomes backgrounded. However, as the verb maintains resolved agreement with both conjuncts, both participants are still portrayed as performing the action together.

In inclusory conjunction, a split by extraction takes the form of fronting the inclusory pronoun to a topical position. This solution is illustrated in Nêlêmwa in (35), an example where the topicalization is justified as a way to assert the creditable source of information to find out about the identity of the secondary conjunct, which is questioned. The position from where the primary conjunct is extracted is indicated by the underscore ( - ).

(35) Nêlêmwa (Austronesian, Oceanic; Bril 2004: 513)

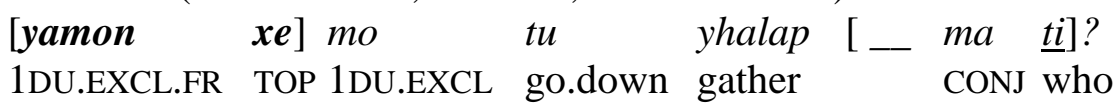

'You, you went food-gathering with whom?' (36).

The schematic syntax of the split applied to an inclusory construction is given in

(36) Split by extraction and the inclusory construction

$$
\begin{array}{lrll}
\text { contiguous: } & \mathrm{V}+\mathrm{DU} / \mathrm{PL} & {\left[\mathrm{PRO}_{1}+\mathrm{DU} / \mathrm{PL}\left[(\& \mathrm{COMIT}) \mathrm{NP}_{2}\right]\right]_{\mathrm{SUB}}} \\
\text { split: } & {\left[\mathrm{PRO}_{1}+\mathrm{DU} / \mathrm{PL}\right]_{\mathrm{TOP} / \mathrm{SUB}}} & \mathrm{V}+\mathrm{DU} / \mathrm{PL} & {\left[\_1\left[(\& \mathrm{COMIT}) \mathrm{NP}_{2}\right]\right]_{\mathrm{SUB}}}
\end{array}
$$

An example of a split by extraction involving summative conjunction is given in (37a) from the Mixtepec dialect of Miahuatec Zapotec, where again the primary conjunct is fronted to a topical position. Another example is (37b), where it is focalized. It should be born in mind at this point that Miahuatec Zapotec, like any other Southern Zapotecan language, uses a quantifier verb instead of a summative pronoun. This was illustrated in example (16) above in $\$ 2.2 .2$. 


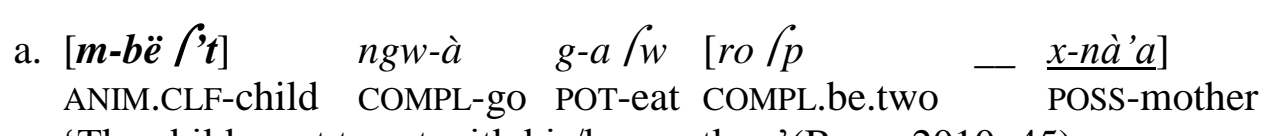

'The child went to eat with his/her mother.'(Beam 2010: 45)

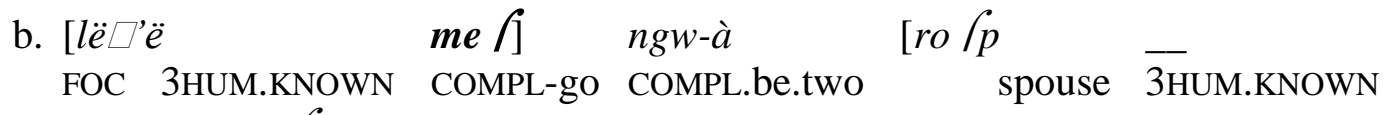
ndá kanı f'
HAB.go dance
'She (was the one who) went with her spouse to dance.' (Beam 2006: 11)

The schematic syntax of this construction is given in (38).

(38) Split by extraction and the summative construction
contiguous:
$\left.\mathrm{V}+\mathrm{DU} / \mathrm{PL}\left[\mathrm{PRO} / \mathrm{V}+\mathrm{DU} / \mathrm{PL}\left[\mathrm{NP}_{1}(\& \mathrm{COMIT})\right) \mathrm{NP}_{2}\right]\right]_{\text {SUB }}$
split:
$\left[\mathrm{NP}_{1}\right]_{\mathrm{TOP} / \mathrm{SUB}} \mathrm{V}+\mathrm{DU} / \mathrm{PL}[\mathrm{PRO} / \mathrm{V}+\mathrm{DU} / \mathrm{PL}[$ $\left.\left.{ }_{1}(\& \mathrm{COMIT}) \mathrm{NP}_{2}\right]\right]_{\mathrm{SUB}}$

The split construction in the specific examples (37) is of special interest here because it serves a special purpose in the grammar of Miahuatec Zapotec, namely, it allows the primary conjunct to be overtly expressed in the clause. This may sound surprising, but Zapotecan languages have a syntactic constraint that bans the overt occurrence of a subject NP that is coreferential with the possessor of some other constituent in the clause. Because of this constraint, the primary conjunct in examples like (37) would not be allowed to surface in subject position. This is where the split construction becomes useful.I will elaborate briefly on this point.

As an illustration of the constraint, consider the examples in (39) from Quiegolani Zapotec. In (39a), there is an explicit NP subject that occurs postverbally. In (39b), the verb shows agreement with a first person subject. In both instances the subject is NOT correferential with a possessor. The examples in (40) contrast with those in (39), where the subject IS correferential with a possessor. In such cases, the subject participant is not expressed in the subject slot (the absence of agreement for first person in (40b) shows the same phenomenon).

(39) Quiegolani Zapotec (Oto-Manguean, Zapotecan; Black 2000)
a. w-eey-t Benit mël
COMPL-take-NEG Benito fish
'Benito didn't take fish.' (173)
b. čin-a? $\quad x$-ičR-bo?
POT.comb-1SG POSSD-head-3FORMAL
'I will combhis hair.' (72)

$\begin{array}{ll}\text { (40) a. bito } b-n e z ̌ R w & \\ \text { not COMPL-give } & b g^{w} e x[\check{c} e \text { no } ? \text { ol- } \leftrightarrow n \text { ?] } \\ \text { broom of woman-the }\end{array}$

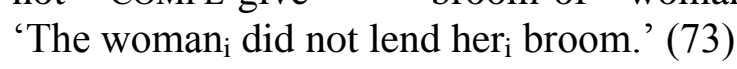

(lit. '( $\left(\mathrm{she}_{\mathrm{i}}\right)$ did not lend the woman ${ }_{\mathrm{i}}$ 's broom.')

b. čin_ $\quad x$-ičR-a?

POT.comb POSSD-head-1SG

'I will comb my hair.'(72)

(lit. ' $\left(\mathrm{I}_{\mathrm{i}}\right)$ will comb my $\mathrm{i}_{\mathrm{i}}$ head.') 
The split in (37) proves one useful way to go around this constraint so that the primary conjunct can be encoded overtly. ${ }^{33}$ Another way could involve the fronting of the entire conjoined NP, as in (41a). These two strategies can be compared with the form a conjoined NP takes when it occurs in situ, shown in example (41b), that is, abiding by the constraint. Here the conjoined NP is subject, but internally, just like in (40) the pronoun $m e \int$ cannot be used to index the primary conjunct, because it is correferential with the possessor.

(41) Miahuatec Zapotec, Mixtepec dialect (Oto-Manguean, Zapotecan)
a. $[l \ddot{e} \square ’ \ddot{e}$
ni $\int \mathrm{t} \ddot{\ddot{e}} \square t$
me $\int$
ro $\int p \quad \underline{b e} \square ’ l$
me f] nhé
$y \grave{u}$ 'g
FOC 3HUM.KNOWN COMPL.be.two sister 3HUM.KNOWN AUX cook food
'It is she and her sister that are preparing a meal.' (Beam 2010: 44)
b. nhé yù'g $[$ ro $/ p$
(*me) $\quad \underline{b e} \square ’ l \quad m e /]$
$n \iota / t y \ddot{e} \square t$
AUX cook COMPL.be.two
sister 3HUM.KNOWN food
'She and her sister are preparing a meal.' (Rosemary Beam, p.c.)

On the other hand, in the non-configurational languages of Australia, where discontinuity of constituents is a characteristic feature of the syntax (Hale 1983, Austin and Bresnan 1996, Haviland 1979, etc.), splits in conjunctional structures naturally occur triggered by the requirements of information structure (Blake 2001).The splits happen alike in inclusory conjunction (42) and in coordinative conjunction (43). In the latter example, the primary conjunct (i.e., the one marked with the coordinator) also appears in a prominent topical position, notice for example the translation.

(42) Inclusory conjunction

Kuuk Thaayorre (Pamanyungan; Gaby 2006: 303)

wey, [ngali] yancm [ngan waanharr $]$ iipal

hey 1DU.EXCL(NOM) go.PL.IMPFV relative brother(NOM) from.there

'Hey, my brother and I have come here.'

(43) Coordinative conjunction ${ }^{34}$

33 As verbs in Miahuatec Zapotec are not targets of plural agreement, examples in (37) could in principle be mistaken as instantiating a comitative structure. However, there is another comitative structure in the language which is not summative as it does not include the reference to the primary conjunct. This construction, shown in (vi), may use the comitative marker kon, borrowed from Spanish con. Notice that in (vi) the primary conjunct is repeated in the comitative structure as a way to maintain co-reference of the possessor with the subject.

(vi) Miahuatec Zapotec, Loxicha dialect (Oto-Manguean, Zapotecan; Beam 2006: 12)
[Pedr] $n g w$ -
zi'n $[$ kon ro $/ p$
xi'n Pedr]
Peter COMPL-go work COMIT COMPL.be.two child Peter
'Peter went to work with his two sons.'

34 An example of a discontinuous conjoined NP functioning as object is given in (vii).

(vii) Kuuk Thaayorre (Pamanyungan; Gaby 2006: 320)
ngul ngay
kirk
kempthe kal-m
thul $=y u k$
then 1SG.ERG spear.ACC apart carry-IMPFV
'I used to carry spears and woomeras separately'
woomera.ACC 
Kalkatungu (Pamanyungan; Blake 2001: 423 apud Bril 2010: 326)

[kintja-(ng)ku=yana] intji-mi-ngi-yu ntiya-(ng)ku [tjipa-yi kurlayingu-thu] female-ERG=and pelt-FUT-me-they.DU stone-ERG this-ERG male-ERG

'The girl and boy will both pelt me with stones.'

In configurational languages, splits by extraction involving coordinative structures are not found, allegedly obeying to the Coordinate Structure Constraint by Ross (1967) (see the examples of Nakanai (Austronesian, Oceanic) in $\S 4$ for a possible counterevidence). In the next section, I present other conjunctional constructions which involve yet another type of split I call 'split by integration'. Such a split has not received much attention in the typological literature but poses, nonetheless, intriguing questions for a natural theory of conjunction.

\subsection{Split conjunction by integration.}

In the previous section, I studied a few cases of splits by extraction where the role of the primary conjunct is made more prominent. In contrast to such splits, speakers may instead want to upgrade the role of the secondary conjunct as a way of reducing the inherent asymmetry between the conjuncts. However, they do it in such a way that the secondary conjunct is still not given equal discourse prominence as the primary conjunct, that is, without resorting to the coordinative structure. All this is achieved by yet another very different type of conjunctional split I call 'split conjunction by integration', whose schematic syntax is given in (44).

(44) Split conjunction by integration

$\left[\mathrm{NP}_{1}\right]_{\text {TOP/SUB }} \mathrm{V}+\mathrm{DU} / \mathrm{PL}$ [COMIT NP $\left.\mathrm{N}_{2}\right]$

The conjunctional structure in (44) involves a split where the NP encoding the primary conjunct is syntactically treated as a canonical topical subject while the secondary conjunct is encoded discontinuously in a comitative phrase. In this respect, the structure in (44) is in essence the comitative structure in (18e) above, repeated here as (45a). The fundamental difference between them lies in the fact that the verb in the construction in (44) shows resolved agreement with both conjuncts, making the structure closer to the coordinative structure in (18a), repeated here as (45b).

$\begin{array}{llll}\text { (45) a. Comitative: } & {\left[\mathbf{N P}_{1}\right]_{\mathrm{suB}}} & \mathrm{V}+\mathrm{SG} & \left.\text { [COMIT } \mathbf{N P}_{2}\right] \\ \text { b. Coordinative: } & {\left[\mathrm{NP}_{1} \& \mathrm{NP}_{2}\right]_{\mathrm{SUB}}} & \mathbf{V}+\mathrm{DU} / \mathbf{P L}\end{array}$

An example of split coordination by integration is given in (46a) in Manambu, an SOV non-Austronesian, Papuan language. This example may be contrasted with the comitative structure in (46b) and the standard coordination construction in (46c). Notice that the conjuncts in (46a) do not form a constituent despite their phonological contiguity because in the contiguous structure in (46c), the comitative coordinator -wais associated with the primary conjunct. ${ }^{35}$

35 Another example of split coordination is found in Tariana, as shown in (viii). Here the secondary conjunct is a list of participants. This structure contrasts with (ix), which has a contiguous conjoined NP.

(viii) Tariana (Arawakan; Aikhenvald 2003: 151)

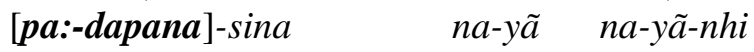

one-CLF.HAB-REM.PST.INFR 3PL-stay 3PL-stay-ANT

[diha di-we-ne-ne

diha ha-niri-nipe-ne 
(46) Manambu (SOV) (Papuan, Sepik; Aikhenvald 2008)

a. $[d \leftrightarrow-k \leftrightarrow d \leftrightarrow \quad$ asa:y $] \quad[n \leftrightarrow k \leftrightarrow-d \leftrightarrow \quad d u-a-w a] \quad$ asa-waata yi-di he-OBL-M.SG father other-M.SG man-LK-COMIT dog.LK-COMIT then go-3PL.BAS.VT 'His father with another man, with a dog then went.' (162)

b. [wun] $[\underline{l \leftrightarrow k \leftrightarrow-w a] \quad \text { warya- } k \quad y i-k-n a-d \leftrightarrow w u n-\leftrightarrow k}$ I She-OBL-COMIT fight-PURP.SS go-FUT-ACT.FOC-1M.SG.BAS.VT-CONF 'I will go to fight with her.' (162)

\section{c. $\left[\begin{array}{llll}a & \text { takwa-wa } & \mathbf{l} \leftrightarrow-k \leftrightarrow \quad \tilde{n} a n\end{array}\right]$ ata $k w a-b \leftrightarrow r$ DEM.DIST.F.SG woman.LK-COMIT she-OBL child then stay-3DU.BAS.VT 'The woman and the child then stayed there.' (160)}

Another language with a similar split is K'ichee', a Mayan language from Guatemala. The split structure is illustrated in (47). For the split to be structurally obvious, the primary conjunct is required to appear preverbally in a topical position; otherwise, as the language has a canonical VOS word order, the common position for the subject is to occur postverbally and it could induce the interpretation of $(47 \mathrm{~b})$, which is an instance of comitative coordination. The comitative construction is given in $(47 \mathrm{c})$ where the verb agrees only with the primary conjunct.

(47) K'ichee' (VOS) (Mayan; courtesy of Telma Can, p.c.)
a. [le achi] x-ee-chaku-n
$[r-u k$,
le $\quad$ nu-xb'aal]

DET man COMPL-3PL.ABS-work-ANTIP 3POSS-and/with DET 1POSS-brother

'The man worked with my brother.' / 'The man and my brother worked.'
b. x-ee-chaku-n [le achi r-uk' le nu-xb'aal] COMPL-3PL.ABS-work-ANTIP DET man 3POSS-and/with DET 1POSS-brother 'The man and my brother worked.'
c. $x$ -
[le achi $] \quad[r-u k$,
le $\quad$ nu-xb'aal]
COMPL-3SG.ABS-work-ANTIP DET man 3POSS-with DET 1POSS-brother
'The man worked with my brother.'

In contrast to K'ichee', in the split construction of Tzotzil, another Mayan language, there is no need for the topical extraction of the primary conjunct because the comitative phrase encoding the secondary conjunct can precede the NP encoding the primary conjunct, and the two phrases could not possibly be interpreted as forming a contiguous constituent.

(48) Tzotzil (VOS) (Mayan; Aissen 1989: 533)

he 3SG.NF-younger.sibling-PL.COMIT he parent-M-PL-COMIT

di-ĩdua-ne di-daki-ne]

3SG.NF-daughter.in.law-COMIT 3SG.NF-grandchild.PL-COMIT

'He [a Tariana] with his younger siblings, with his parents, with his daughter-in-law, with his grandchildren, stayed in one house.'

(ix) na:ka neyù na: [di-we-ri di-phe-ri-ne]

3PL.come 3PL+climb 3PL.go 3SG.NF-younger.sibling-M 3SG.NF-elder.sibling-M-COMIT

'They came up, the younger and the elder brother. 


$\begin{array}{lllll}\text { ?i-ve?-ik } & {[x c h i ? u k} & j \text { jkaxlan }] & {[l i} & \text { Xun=e }] \\ \text { COMPL-eat[3ABS]-PL } & \text { with } & \text { Ladino } & \text { DEF } & \text { Xun=ENCL } \\ \text { 'Xun ate with the Ladino.' } & & & \end{array}$

The split structure in (44), illustrated in (46a), (47a) and (48), is a unique hybrid of the comitative and the coordinative structures which nicely combines the functional strengths of both constructions. On the one hand, the resolved agreement on the verb semantically portrays both conjuncts equally as co-actors in the event. This morphological mechanism proves successful at increasing the degree of symmetry between the conjuncts, and in this respect, it reminds one of the function of coordination. On the other hand, the syntactic discontinuity of the conjuncts allows the introduction of the primary conjunct as a more topical participant than the secondary conjunct, and in this respect it reminds one of the asymmetries proper of the comitative construction.

In syntactic terms, the split in (44) is structurally analogous to the comitative structure in (45a) and it is thus sensible to account for it as having developed from the comitative structure by adding resolved agreement on the verb. I can think of at least four arguments in favour of such an analysis. Firstly, the split in (44) always involves a comitative linker and never a canonical and-type ofcoordinator. However, the fact that a language makes use of a comitative linker as a coordinator does not imply that it will allow the split. This is for instance illustrated by the ungrammaticality of (49) in Chilean Spanish. ${ }^{36}$

(49) Chilean Spanish (Schwartz 1988b : 64)

*[yo] fu-imos a-l cine [con mi madre]

I go.PST-1PL to-DEF.SG cinema with 1POSS mother

Intended meaning: 'My mother and I went to the cinema.'

Secondly, the syntactic position of the secondary conjunct in the split structure is the same as a canonical comitative participant. Thirdly, the two conjuncts in either structure are also treated alike for the purposes of information structure. In other words, the primary conjunct is topical in either structure and thus may serve as an established topic for the following discourse. In contrast, the secondary conjunct in either structure works as an anti-topic; that is, it may become the topic for the following discourse.

A clear example of the topicality of the primary conjunct in splits of this kind is seen in colloquial Hausa in example (50). Here the primary conjunct appears preverbally, while the secondary conjunct follows the verb in the comment string of the utterance. According to Abdoulaye (2004), the split in (50a) responds to the pressures of information structure and is a common reply to the question 'where is Abdu?' In (50b), it is further shown that the NP Abdù is the established topic in the following string of discourse as it cannot be repeated, but the secondary conjunct can.

(50) Hausa (Afro-Asiatic, Chadic; Abdoulaye 2004: 187)

a. [Abdù] sun tàfi makar)antaa [dà Bàlki]

Abdu 3PL.PFV go school and/with Balki

'Abdu went to school with Balki,'

36 The same case is illustrated for Russian in McNally (1993: 353). 

b. an bâa [*Abdì]/[Bàlkî $]$ àlloo
IMPS.PFV give Abdu/Balki board
and a writing board was given to *Abdu/Balki.'

The primary conjunct of the split structure in (50a) is treated like the topical subject of the comitative strategyin (51a). This may again be seen in the behaviour of (51b). The same applies to the secondary conjunct.

(51) Hausa (Afro-Asiatic, Chadic; Abdoulaye 2004: 181)
a. [Abdì] yaa
tàfi makar)antaa $[$ dà Bàlki $]$
Abdu 3SG.M.PFV go school with Balki
'Abdu went to school with Balki,'
b. an bâa [*Abdù]/[Bàlkî $]$ àlloo
IMPS.PFV give Abdu/Balki board
'and a writing board was given to *Abdu/Balki.'

In contrast, in the coordinative strategy in (52a) both participants are equally topical and either of them can be elided (if chosen as topic) or repeated (if chosen as anti-topic) in the following context. This is shown in $(52 b)$.

(52) Hausa (Afro-Asiatic, Chadic; Abdoulaye 2004: 181)

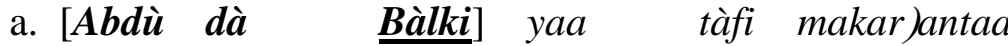
Abdu and/with Balki 3PL.PFV go school
'Abdu and Balki went to school,'
b. an bâa [Abdù $]$ B Bàlkî $]$ àlloo
IMPS.PFV give Abdu/Balki board
'and a writing board was given to Abdu/Balki.'

Finally, there are three languages in Stassen's (2003) sample which do not appear to have a coordinative structure: Tolai (Austronesian, Oceanic), Acooli (Nilo-Saharan, Nilotic) and Tera (Afro-Asiatic, Chadic). Accordingly, the closest equivalent to the symmetrical semantics evoked by a coordinative strategy in other languages is expressed in these languages by means of a split structure, as shown by the contrast in the translation between (53a) and (53b).

(53) Tolai (Austronesian, Oceanic; Mosel 1984: 176)
a. [nam ra tutana] $\boldsymbol{i}$ ga rovoi [ma ra DEM ART man he TA hunt with ART dog 'That man hunted with the dog.'
b. [Telengai] dir rovoi [ma $\quad$ ra $\quad$ pap $]$ Telengai they.DU hunt and/with ART dog 'Telengai and the dog hunted.'

In the light of this evidence, the split construction in (44) inherits the discontinuity of the conjuncts typical of a comitative structure.I call this split 'split conjunction by integration' using the term 'integration' to indicate that the upgradingof the secondary conjunct as an equal co-actor in the event is achieved by its semantic 'integration' into the 
core of the verb by means of resolved agreement.Nonetheless, while the comitative construction may well be the source of thisconjunctional structure, at least for the instances presented so far (see $\$ 3.4$ for other possibilities), how the resolved agreement on the verb is achieved remains an intriguing question.

As a possible answer to such a question, one may want to view the agreement on the verb as having a semantic function rather than a morphosyntactic one. In this respect, in an influential article for a theory of agreement, Corbett (1988) introduces a number of problematic cases in the Slavonic languages where plural agreement does not respond to requirements of the syntax as is otherwise expected in more canonical cases. ${ }^{37}$ An exemplary case for this deviation is the associative construction found in Talitsk Russian, as in (54), where a plural verb can be used with a singular NP subject "to indicate that the noun refers to a person or persons besides the one indicated directly" (p. 36). Since then, a similar construction has also been reported in other languages, for example in Maltese, as shown by the contrast between (55a) and (55b).

(54) Talitsk dialect of Russian (Bogdanov 1968, apud Corbett 1988: 36)

M'it'ixa dra-l'-i-s'

Mitixa fight-PST-PL-REFL

'Mitixa (and his wife) had a fight.'

(55) Maltese (Semitic; Fabri 1993: 276-278, apud Corbett 2000: 191)
a. Brian gie
Brian came.3sG
'Brian came.'

\section{b. Brian $\dot{\boldsymbol{g} e w}$}
Brian came.3PL
'Brian and his family/friends came.'

This associative construction is also found in the Mayan languages K'ichee' and Tzotzil. Example (56) illustrates it in Tzotzil. Similarly, the split examples in (47a) and (48) could also have the alternative interpretations 'the man and some other people worked with my brother' and 'Xun and some others ate with the Ladino', respectively.

(56) Tzotzil (VOS) (Mayan; Aissen 1989: 533)

$\begin{array}{lll}\text { ?i-ve } \text {-ik } & {[l i} & \text { Xun=e }] \\ \text { COMPL-eat[3ABS]-PL } & \text { DEF } & \text { Xun=ENCL }\end{array}$

'Xun ate with someone.' or 'Xun and some others ate together.'

37 For example, plural agreement with a singular NP subject is used to indicate respect, as in the old construction in $(\mathrm{x})$.

(x) Russian (Turgenev Nakanune, 1860, Corbett 1983: 25)

[mamen'ka] plačut -šepnula ona vsled uxodivšej Elene-

mother cry(PL) whispered she after leaving Elena

a [papen'ka] gnevajutsja

and father are.angry

" "Your mother is crying", she whispered after Elena, who was leaving, "and your father is angry".' 
To account for (56), Aissen (1989) proposes that proper nouns in Tzotzillike Xun'John' can have a group interpretation and thus can trigger plural agreement on the verb. In K'ichee' the construction also allows common nouns providing they have a specific referent. In this respect, Aissen advances an analysis for the split structure in (48) as being a natural extension of the associative construction. The extension happens when the companion participant encoded in the comitative phrase, the secondary conjunct, is identified as the associate member of the set evoked by the group interpretation of the noun indicating the primary conjunct. The reading involving only two people is possible because there is no a priori expectation that the set evoked should include more than two members.

In this view, split conjunction by integration results from a semantic extension of the associative construction. However, it should be born in mind that not all languages that have the associative construction allow the two-participant interpretation proper of the split construction. This is illustrated by Maltese, where the example in (57) can only have a group interpretation, but never one that includes the secondary conjunct.

(57) Maltese (Semitic; Maris Camilleri, p.c.)

[Brian] gew fil-karozza [mal-president]

Brian came.3PL in.DEF-car with.DEF-president

'Brian (and others) came with the president.'

*'Brian came with the president.'

In this section, I introduced some illustrative cases of split conjunction by integration. A construction bearing this type of conjunctional split has the two conjuncts encoded discontinuously in the clause in the same way as a comitative structure, but the verb shows resolved agreement to indicate that the secondary conjunct has been semantically integrated in the event as an equally participating co-actor. The split is functionally motivated by a desire to reduce the asymmetry between the two conjuncts by upgrading the role of the secondary conjunct. I have further proposed that a construction that shows split conjunction by integration is commonly based on a comitative structure and emerges by using dual or plural resolved agreement on the verb. One of the possible ways verbal agreement is implemented is via the exploitation of the possibilities provided by an associative construction of the same type found in Talitsk Russian or Maltese. However, it still remains an open question whether all the languages that display split conjunction by integration have such an associative construction. As I show in the next section, there are some other more extreme cases of split conjunction by integration that are not based on an alternative comitative structure.

\subsection{Exploring the limits of splitsby integration.}

3.4.1. Severe split conjunction. There are other conjunctional constructions which bear a type of split that reminds one of the splits by integration in the previous section, but which are not based on a readily available comitative structure. In other words, such constructs are not structurally related to a comitative structure of the standard type. Because of this, they function as fully independent constructions for the encoding of conjunctional semantics. Nevertheless, I still treat them as a subtype of split conjunction by integration because of two reasons: (i) they respond to the very same functional motivation as the cases presented in the previous section and (ii) they share a considerable degree of structure with them. However, it is important to distinguish them clearly as a different ontology, and to do so, I treat these new cases as instances of 'severe split conjunction by integration', abbreviated as 'severe split conjunction', with the schematic syntax in (58). 
In the light of these severe cases, the instances presented in the previous section could be revisited as instances of 'mild split conjunction by integration', whose schematic syntax is repeated in (59) for convenience.

(58) Severe split conjunction by integration

$\left[\mathrm{NP}_{1}\right]_{\text {TOP/SUB }} \mathrm{V}+\mathrm{DU} / \mathrm{PL} \quad\left[\mathrm{NP}_{2}\right]$

(59) Mild split conjunction by integration

$\left[\mathrm{NP}_{1}\right]_{\mathrm{TOP} / \mathrm{sub}} \mathrm{V}+\mathrm{DU} / \mathrm{PL}$ [COMIT NP $\left.\mathrm{N}_{2}\right]$

In severe split conjunction, the two conjuncts occur in different positions in the clause just like in the mild cases, but the secondary conjunct is promoted by the construction as an argument of the verb and it is thus encoded as an unmarked anti-topic NP.

Constructions showing severe split conjunction are found in three unrelated language groups of the Americas. In North America, it occurs in the Eastern Algonquian languages Passamaquoddy and Mi'kmaq, while in Mesoamerica it is found in the languages of the Otomi-Mazahua subgroup of Oto-Manguean and in Misantla Tononac of the Totonac-Tepehua family. The data further suggest that the constructions in Algonquian and the Otomi-Mazahua instantiate a similar type of construction, whereas the one of Misantla Totonac instantiates its own type. Because of this, it is sensible to present them separately. The extent to which severe split conjunction occurs in the languages of the world goes beyond my knowledge, but one can hypothesize that the phenomenon will be found in linguistic areas or linguistic families where the asymmetrical encoding of conjunctional semantics is favored over the symmetrical one.

Severe split conjunction has been reported in Passamaquoddy in Bruening (2003, 2004, 2005) who treats it as a case of 'split coordination', also found in closely related Mi'kmaq in a manuscript by Carlos Quicoli mentioned in Bruening (2005). The construction in question is illustrated in (60). The primary conjunct appears in the position dedicated to a topical subject, the secondary conjunct appears postverbally, and the verb shows resolved agreement in the plural.

(60) Passamaquoddy (Algic, Algonquian; Bruening 2005: 5)

[Piyel $]$ ali-wiciyew-t-uwok [Mali-wol $]$

Piyel around-go.with-REC-3PL Mary-OBV

'Piyel and Mary are going around with each other.'

A similar construction is also found in the Otomi-Mazahua languages of Mexico. The case is illustrated in Toluca Otomi in (61) and in Highlands Otomi in (62), which make use of verb agreement in the dual. Notice that these languages instantiate two different word orders, but in both cases the primary conjunct occurs in the position of subject. $^{38}$

(61) Toluca Otomi (SVO) (Oto-Manguean; Otomi-Mazahua; modified from Lastra 1989: 121)

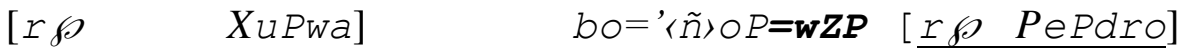

SG John 3.PST $=\langle$ SS $\rangle$ walk $=$ DU SG Peter

'John came with Peter.'

38 The primary conjunct in a VOS language like Highlands Otomi can also be moved to preverbal position. This happens when it is highly topical as in example (68) further below. 
(62) Highlands Otomi (VOS) (Oto-Manguean; Voigtlander and Echegoyen 1979: 307)

KbYh=mi [raP ndqmbe $] \quad[n)$ ra t'Yhni]

[3.PRES]live $=$ DU SG.3POSS grandmother DEF.SG SG child

'That child lives with his grandmother.'

On the surface, these constructions show structural resemblance to mild instances of split construction by integration. One fundamental difference lies in the fact that the NP of the secondary conjunct is not introduced by a coordinator. In other words, the secondary conjunct is encoded in an unmarkedNP. Evidence that there is no underlying zero coordinator comes from the fact that there is no asyndetic coordination in these languages. This is shown by the impossibility of the (a) examples in (63-64). Alternatively, as shown in the (b) examples, the languages also have a syndetic construction that is only used extremely rarely and under very specific circumstances. For example, the coordinative structure of Toluca Otomi in (64b), an instance of comitative coordination (with the borrowed marker ko 'with' from Spanish), is only used to emphasize that the participants acttogether. ${ }^{39}$

(63) Passamaquoddy (Algic, Algonquian; Bruening 2005: 5)

a. *[Piyel Mali(-wol) $]$ ali-wiciyew-t-uwok

Piyel Mary-OBV around-go.with-REC-3PL

'Piyel and Mary are going around with each other.'

b. [Piyel naka Mali] ali-wiciyew-t-uwok

Piyel and Mary around-go.with-REC-3PL

'Piyel and Mary are going around with each other.'

(64) Toluca Otomi (Oto-Manguean; Otomi-Mazahua)

a. *[rø XuPwa $\left.\begin{array}{llll}r \wp & P e P d r o\end{array}\right] \quad b o={ }^{\prime}\langle\tilde{n}\rangle O P=w i$

SG John SG Peter 3.PST $=\langle\mathrm{SS}\rangle$ walk $=$ DU

Intended reading: 'John came with Peter.'

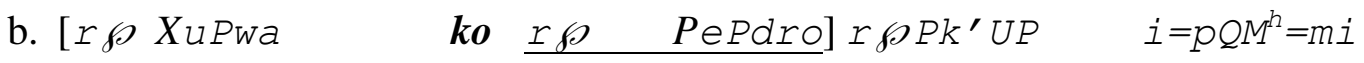 SG John and/with SG Peter together 3.PRES.REAL=work.AS=DU
'John and Peter work together.' (Lastra 1989: 121)

Furthermore, this split structure is not structurally based on a comitative structure, but works independently from it if such a comitative construction exists. For example, while the split structure is the old and native Otomi-Mazahua means to encode conjunctional semantics, some Otomi languages have also borrowed a comitative construction from Spanish, but this is used only rarely, most significantly in the situations where the native structure has distributional restrictions (see §3.4.2) or as a stylistic alternative to it. The later point is illustrated in the textual extract in (65) from San Ildefonso Otomi. Compare for this purpose the split structure in $(65 \mathrm{c})$ with the comitative construction in (65b) and (65e).

(65) San Ildefonso Otomi (Oto-Manguean; Otomi-Mazahua)

39 Notice also the co-occurrence of the predicative $r \wp P k^{\prime}$ ' $U P$ 'together'. 


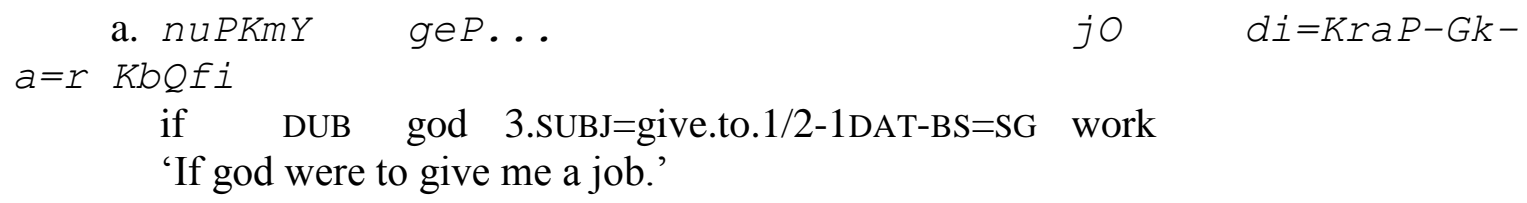
b. $g a=m-p Q f-i \quad\left[\begin{array}{ll}\text { ko } & \text { ngeP=KAP}\end{array}\right]$
1.PRES.IRR=ANTIP-work-FS with FOC $=3 \mathrm{SG}$
'I'd work with that one.'
c. $\operatorname{nuPKmY}\left[\begin{array}{ll}=r & \text { zithU }\end{array}\right] \quad$ ga=n-thQP=KbeP
if $=$ SG devil 1.PRES.IRR=MIDDL-meet=DU.EXCL
'If I'd meet the devil.'

d. $d i=K r a P-G k-a=r \quad K b Q f i$

3.SUBJ=give.to. $1 / 2-1 \mathrm{DAT}-\mathrm{BS}=\mathrm{SG}$ work

'(And if) he were to give me a job.'

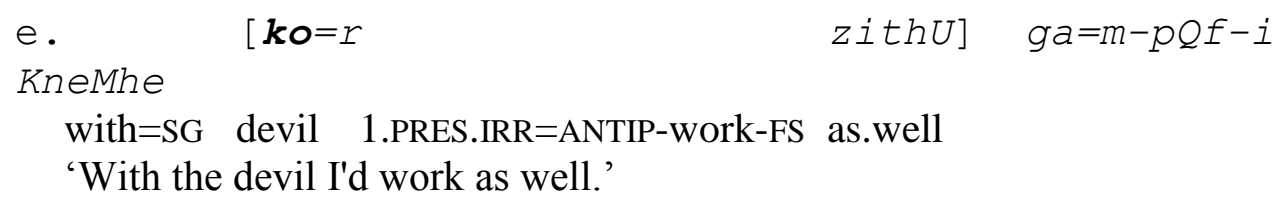

In severe split conjunction, the conjuncts are treated as different constituents, and both can be fronted independently for questioning, relativization or focus. Examples in (66) show questioning in Passamaquoddy (the literal translation is Bruening's; the idiomatic translation is mine). The examples in (67) are again from San Ildefonso Otomi. In (67a), the secondary conjunct is external topic,recovered in the clause by the resumptive pronoun noP. In (67b), it is internal focus, just like in (65c). In the Otomi examples, the primary conjunct is elided because it is the established topic. This elision further illustrates the fact that one can have splits by elision within splits by integration (see $\S 4$ for a discussion).

(66) Passamaquoddy (Algic, Algonquian; Bruening 2005: 6)
a. [Wen] ali-wiciyew-ti-htit
[Mali-wol $]$ ?
who around-go.with-REC-3PL.CONJTV Mary-OBV
'Who is going around with Mary?'
(lit. 'Who are and Mary going around with each other?')
a. [Wen-il $]$ [Piyel $]$ ali-wiciyew-ti-htic-il __?
who-OBV Piyel around-go.with-REC-3PL.CONJTV-PART.OBV
'Who is Piyel going around with?'
(lit. 'Who are Piyel and going around with each other?')

(67) San Ildefonso Otomi (Oto-Manguean; Otomi-Mazahua; Palancar 2009: 565-66)

\footnotetext{
a. $[n O M=K O P=r$

zqqune $], \quad[\underline{n O P}]$

$h Z P n=t o P$

$d a=\tilde{n}-$

$h \ddot{u} P X=k w Z P$

DEF.SG=DEM.III.SG=SG wizard 3SG NEG=someone 1.PRES.IRR=MIDDL=sit.on. $\mathrm{AS}=\mathrm{DU}$

'That wizard, he has no equal.' (lit. 'nobody sits at the same level with him.')
} 
PARTCL NARR.FOCUS DEF.SG=SG serpent 3.IMPF=sleep. $A S=D U$ daily=PARTCL

'And she used to sleep daily with the serpent.'

While the role of the primary conjunct as topical subject is relatively straightforward because of its position, it is less clear what the syntactic role of the secondary conjunct can be in these constructions. I address this question briefly in the following section.

3.4.2. The secondary conjunct in severe split conjunction. The secondary conjunct in severe split conjunction is encoded as an unmarked NP. There is evidence that points in the direction that this NP is not treated as an adjunct by the syntax, but as an argument of the verb. In this sense, the construction can be seen as promoting the secondary conjunct to argument status, much in the vein of comitative applicative constructions. Nevertheless, the syntactic function of this new argument encoding the secondary conjunct remainsdifficult to characterize. In this section, I conclude that perhaps the best analysis is to treat it as a second subject.

The status of the secondary conjunct as an argument is clearer in a number of Otomi languageswhose verbs display a number of interesting asymmetries for the syntax of agreement. In such languages (most notably in all Otomi languages except Toluca Otomi and South Western Otomi), verbs must show resolved agreement in the split conjunction construction, but outside it no verb can agree with a third person plural or dual subject. This is illustrated in the textual extract in (68) from Highlands Otomi. Example (68a) is an instance of severe split conjunction, and dual resolved agreement on the verb is obligatory. ${ }^{40}$ In contrast, the verb cannot agree in number in the clause in $(68 \mathrm{~b})$ with the third person dual subject, only in person.

(68) Highlands Otomi (Oto-Manguean; Otomi-Mazahua; Echegoyen and Voigtlander 2007: 49)
a. $[n u=n a$
zi xitsu]
[a
$\operatorname{raP}$
$n d q]$
$i=K b Y m-m a n h o *(=w i)$
DEF=DET.SG DIM woman 3.PRES.REAL=live.AS-good=DU DEF.SG SG.3POSS man
'The lady lives well with her husband.'
b. $\quad h i n j A m K b Y$ di-n-tsY-i/*di-n-tsYh=mi
never [3.PRES.REAL]INFL-MIDDL-fight-FS/[3.PRES.REAL]INFL-MIDDL-fight.AS=DU
'They never fight.'

As a consequence of these distributional asymmetries, the use of resolved agreement in the verb is a clear indication that the structure in question is an instance of split conjunction. In this respect, consider first example (69). This is the most natural rendering in Santa Ana Otomi for the semantics of the comitative structure in English, but it could equally be said to translate the semantics of the coordinative structure.

(69) Santa Ana Otomi (Oto-Manguean; Otomi-Mazahua; Selene Hernández, p.c.)

$\left[\begin{array}{ll}a & h A^{\prime} i\end{array}\right] \quad b i=n-t s i-h m e=w i[=\underline{n} Y]$

DEF.SG man 3.PST $=$ ANTIP-ingest-tortilla $=\mathrm{DU}=\overline{\mathrm{DEM}} . \mathrm{SG}$

40 The dual marker $=w i$ also encodes dual for the first and the second person. The language has a dedicated morpheme to encode the dual of the first person exclusive. Because of this, when $=w i$ is associated to the first person, it realizesan inclusive value. 
'The man ate together with him'/'The man and him ate together'

Notice that the enclitic pronoun $n Y$ serves as anaphora to the secondary conjunct, hence the translation. The use of this anaphora is the most natural choice in the language, but a marker encoding third person object anaphora is not strictly necessary. Consequently, example (70), although less natural, remains grammatical.

(70) Santa Ana Otomi (Oto-Manguean; Otomi-Mazahua; Selene Hernández, p.c.)

[ a $\left.h A^{\prime} i\right] \quad b i=n-t s i-h m e=w i$

DEF.SG man 3.PST=ANTIP-ingest-tortilla=DU

'The man ate together with him'/'The man and him ate together'

*'The man and some other (unidentified) person ate together.'

What is crucial for our purposes is that example (70) is not an instance of an associative construction of the same type we observe in Tzotzil or K'ichee' where the presence of the associative participant is not explicit. ${ }^{41}$ The structure in (70) is always interpreted with an elided secondary conjunct (this is indicated by the underscore). When the secondary conjunct is restored in an NP, it must occur in a different constituent than the primary conjunct, like in (71a). If the secondary conjunct was restored by means of the coordinative strategy in (71b), the verb does not show number agreement. If number agreement were to be used in the verb, the construction would require plural as in $(71 \mathrm{c})$. This reveals that the structure has an inherent split requiring the secondary conjunct as an argument, so that the conjuncts involve three participants now: the man and the priest, and another person.

(71) Santa Ana Otomi (Oto-Manguean; Otomi-Mazahua; Selene Hernández, p.c.)

$$
\begin{aligned}
& \text { a. }\left[\begin{array}{ll}
a & h A^{\prime} i
\end{array}\right] \quad b i=n-t s i-h m e=w i \\
& \text { [a } m b C h A]
\end{aligned}
$$

DEF.SG man 3.PST=ANTIP-ingest-tortilla=DU DEF.SG priest

'The man ate together with the priest.'/'The man and the priest ate together.'

b. $\quad\left[\begin{array}{lllll}a & h A^{\prime} i & K n e & a & m b C h A\end{array}\right]$ bi=n-tsi-
$\begin{aligned} & \text { hme } \\ & \text { DEF.SG man and DEF.SG priest }\end{aligned}$
'The man and the priest ate together.'

c. $\left[\begin{array}{lllll}a & h A^{\prime} i & \text { Kne } & \text { a } & \end{array}\right.$

DEF.SG man and DEF.SG priest 3.PST=ANTIP-ingest-tortilla=PL/DU

'The man and the priest ate with him.'

${ }^{41}$ On the other hand, an associative construction with a verb in the plural is found in Plains Cree, another Algonquian language like Passamaquoddy. This is illustrated in (xi). Whether a similar construction exists in Passamaquoddy, I do not know, but if it does, it could account for the existence of the split construction in the same way as for the Mayan case presented above.

(xi) Plains Cree (Algic, Algonquian; Ahenakew and Wolfart (1992:373), H.C. Wolfart, p.c. apudDaniel and Moravcsik 2005)

ékot $[a]$ annima Macõhõsis kã-kĩ-ayã-cik

there indeed Macohasis COMP-PRF-live-3PL

"...that, indeed, Macohasis and others used to live there" 
The split between the conjuncts is so severe that the verb can even receive two distinct anaphoric pronouns for each conjunct, as in (72) from San Ildefonso Otomi.

(72) San Ildefonso Otomi (Oto-Manguean; Otomi-Mazahua; Palancar 2009: 587)

ha $n-j a-G p-i$

how [3.PRES.REAL]MIDDL-make-3DAT-FS

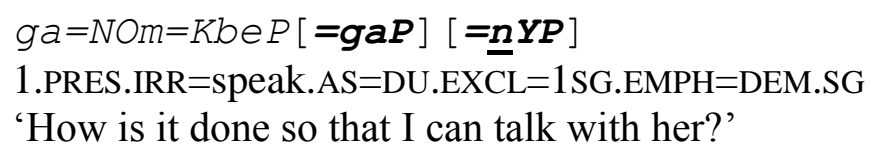

To account for these facts, I propose thatsevere split conjunction is a mechanism to promote the secondary conjunct to argument position. The question still remains of what syntactic role this new argument has.

In principle, it could be argued that it functions as an object. Such an account would have the advantage of making severe split conjunction typologically coherent with the peculiar abundance of comitative applicatives in the languages of North America which promote comitative adjuncts to object position (Stassen 2003). To North America, we caneasily add the languages of Mesoamerica as well as comitative applicatives are widely found in the heavily synthetic families Mixe-Zoque and Totonac-Tepehua, ${ }^{42}$ for example in (73) from Upper Necaxa Totonac. But most notably, they are also found in a number of Oto-Manguean languages where applicatives are not that common. For the latter cases, the applicative is often a transparent emergent structure from the incorporation of the comitative coordinator, although not always. The case is illustrated in (74) from Zoochina Zapotec, a VSO language.

(73) Upper Necaxa Totonac (Totonac-Tepehua; Beck 2004: 62)

tu: $\quad$ ik-lakaskín na-[kin]-ta:-pína...

NON.HUM.REL 1SG.SUB-want FUT-1OBJ-COMIT-go:2SUB.IMPFV

'What I want is for you to go with me.'

(74) Zoochina Zapotec (Oto-Manguean, Zapotecan; López 2009: 115)
a. $n h a \square b$-yêgh

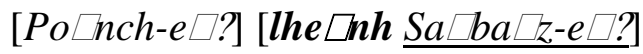
and COMPL-go.SG Alfonso-DET with Sabás-DET
'And Alfonso went with Sabás.'
b. nha $\square b$-yêgh-lhe $\square$ hh $\quad[P o \square n c h-e \square$ ?] $[\underline{S a \square b a \square z-e \square ?]}$
and COMPL-go.SG-COMIT Alfonso-DET Sabás-DET
'And Alfonso went with Sabás.'

In this respect, the secondary conjunct of severe split conjunction appears to share a number of properties with objects, although only indirectly. ${ }^{43}$ For example, it occurs in the

42 Recently, Brown et al. (2011) have proposed that Mixe-Zoque and Totonac-Tepehua are genetically related in a group they call 'Totozoquean'.

43 In the Algonquian languages, the secondary conjunct is always encoded as obviative. In these languages, when a given clause involves two third person participants, they are ranked 
same syntactic position as an object. As an illustration, consider (75), where I show that in San Ildefonso Otomi no adjunct can intercede between the verb and the conjunct; itself a characteristic behavior of objects.

(75) San Ildefonso Otomi (Oto-Manguean; Otomi-Mazahua; Palancar 2009: 564)

$\begin{array}{lll}\text { a. haPbY } & g Z P=\mathrm{pQ}=w Z P & {\left[\begin{array}{ll}\mathrm{ma} & n O M n O\end{array}\right]} \\ M K o P n d C & \end{array}$

where 2.PRES.IRR=go.DU=DU 1POSS mother Mexico

'...where you went with my mother to Mexico.'

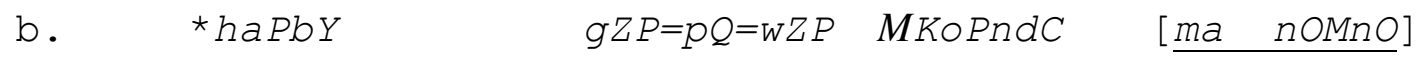

where 2.PRES.IRR=go.DU=DU Mexico 1POSS mother

Intended reading: '...where you went to Mexico with my mother.'

Similarly, in both Algonquian and Otomi-Mazahua, the construction is only possible with intransitive verbs, as illustrated by the ungrammaticality of (76-77). ${ }^{44}$ This restriction could be interpreted as resulting from the existence of a covert comitative applicative that turns the intransitive verb into a transitive oneand treats the secondary conjunct as an object; banning verbs which are inherently bi-actantial.

(76) Passamaquoddy (Algic, Algonquian; Bruening 2005: 8)

*[Mali] nomiy-a-wa-l [Piyel-ol] Susehp-ol Kehlis-k

Mary see-DIR-3PL-OBV Piyel-OBV Susehp-OBV Calais-LOC

Intended reading: 'Mary and Piyel saw Susehp in Calais.'

(77) San Ildefonso Otomi (Oto-Manguean; Otomi-Mazahua; Palancar 2009: 561)

*daP $=t C m=K e P \quad[n o P$ ma Kindo]

1.PST-buy.AS[3OBJ]=DU.EXCL DEF.SG 1POSS brother.of.woman

Intended reading: 'I bought it with my brother.'

In this connection for example, in the Mixean languages (Mixe-Zoquean), aMesoamerican language family, comitative applicatives are only restricted to intransitive verbs (Zavala Maldonado 2012). This is illustrated in Olutec in (78). Compare (78a) with the impossibility of (78b), for which the only encoding alternative is (78c). ${ }^{45}$

attending to information structure principles so that the one ranking lower is marked as obviative; a grammatical person which is often treated as a fourth person. Objects often are obviative participants, as for example in (xii). However, obviation is not a reliable diagnostic for objecthood, and thus cannot help to discern the role of the secondary conjunct in severe split conjunction. I want to thank the second anonymous referee for this observation.

(xii) Passamaquoddy (Algic, Algonquian; Mitchell 1921/1976: 7 apud Bruening 2003: 5)

koluskap 't-oli asitem-a-l nicalku-l

Koluskap 3-thus answer-DIR-OBV 3.uncle-OBV

'Koluskap answers his uncle'

44 The only exception are a group of defective transitive verbs in Passamaquoddy which do not allow the direct/inverse indexing proper of more canonical transitive verbs, and which have a word order such as NP1 V NP2 OBJ.

45 The restriction does not exist in the Zoquean languages. In Mixean languages, a combination of the comitative and the instrumental applicative is used for transitive verbs. For more details, see Zavala Maldonado (2012). 
(78) Olutec(Mixean; Mixe-Zoquean)
a. porke $\quad \tan =\mathbf{m}):-k a y-a m=a k$
[kumpa:ne]
because $1 \mathrm{~A} . \mathrm{INDP}=\mathrm{COMIT}-\mathrm{eat}-\mathrm{IRR}$.INDP=ANIM buddy

'Because I'm going to eat with my buddy.'(Zavala Maldonado 2000: 815)

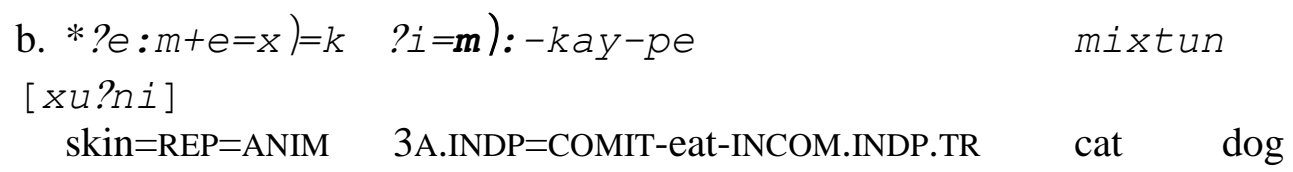

However, an analysis of severe split conjunction based on a covert applicative would not account for the presence and relevance of verb agreement, which is so entrenched that it goes beyond the morphosyntax of affixal morphology. For example, a suppletive form of the intransitive verb 'go' must be used in the split construction in both these families when the subject is dual. ${ }^{46}$ The selection of alexical root can only be accounted for as motivated by a resolved agreement triggered by the subject.

(79) Passamaquoddy (Algic, Algonquian; Bruening 2005: 6)
[Mali] al-kawtuw-ok
[Piyel-ol]
Mary around-walk.DU-3PL Piyel-OBV
'Mary and Piyel are walking around.'

(80) San Ildefonso Otomi (Oto-Manguean; Otomi-Mazahua; Palancar 2009: 567)

$$
\begin{aligned}
& b i=m \boldsymbol{Q}=w Z P[=r \quad Z U K w Q] \\
& \text { 3.PST=SS/go.DU=DU=SG Devil } \\
& \text { 'He went with the Devil.' }
\end{aligned}
$$

An alternative solution to account for the role of the secondary conjunct in severe split conjunction is to analyze it as a second subject. Such an analysis was first advanced in Bruening (2005) who treats it as a case of what he calls 'split coordination' framed in the Principles and Parameters theory. The construction would involve generating the second subject in a second specifier of little $\mathrm{vP}$ by a type-shifting rule for multiple specifiers. In this account, the primary conjunct is generated in the first specifier of $\mathrm{vP}$ and is then moved to the topical position, whereas the NP generated in the second specifier (i.e. the secondary conjunct) is left in situ. The verb shows resolved agreement with both, because both are subject. The structure described is given in Figure 1.

\section{INSERT FIGURE 1 ABOUT HERE}

The analysis of the secondary conjunct as a promoted second subject has two main advantages. It takes into account the argument status of the secondary conjunct and the

46 The case at hand is of root suppletion, not of verbal number. 
different distributional properties associated with such status, and it accounts for the use of resolved verbal agreement.

In this connection, a conjunctional construction featuring severe split conjunction with a second subject is also found in Misantla Totonac, another American Indian language of Mexico. This language is unique within the Totonac family because it does not have a comitative applicative that promotes the secondary conjunct to object position as it is common in the rest of the family (cf. example 73). In the split construction of Misantla Totonac, the NPs realizing the conjuncts also occur in different positions in the clause; the primary conjunct appearing in preverbal position. This is shown in (81).

(81) Misantla Totonac (Totonac-Tepehua; MacKay 1999: 300)

[Pedro] laa-laqa...n-yaa-na [ [کSwáan]

Peter [3SUB]REC-see[3OBJ]-IMPFV-COMIT John

'Peter saw it(/him/her/them) with John.'

The main difference between the Algonquian/Otomi-Mazahua case and the construction in (81) lies in the fact that in Misantla Totonac the verb is marked with the comitative suffix $-n a$, which anchors the conjunction relation between the two $\mathrm{NPs}^{47}$ but also the construction requires the reciprocal prefix laa- (MacKay and Trechsel 2003).MacKay (1999) claims that the two conjuncts are both treated as subject. ${ }^{48}$ In most cases, the morphotactics of the verbal complex does not allow the co-occurrence of two subject pronominal indexes, and consequently only one subject affix is used. This only affix indexes the person ranking higher in the person hierarchy. ${ }^{49}$ This is shown in (82) where the verb has the subject prefix for the first person. Notice, however, that the first person is treated by the syntax as the secondary conjunct(the idiomatic translation is mine; while the literal one is MacKay's, which tries to reflect the complex semantics of the construction with the double subject). ${ }^{50}$

(82) Misantla Totonac (Totonac-Tepehua; MacKay 1999: 292)

[wi...š $]$ ik-laa-ca...a...la-yaa-na [kit $]$

you(SG) 1SUB-COMIT-run-IMPFV-COMIT I

'You run with me.'

(lit'You run with me, I run with you.')

There are also cases where the verb can reveal indexing of both subjects. This happens when one of the conjuncts is a third person plural, as in (83a) and (83b). Here the verb indexes this participant by the prefix $t a-$, which indicates 'plural subject', as shown in (83c). Example (83a) further shows that transitive verbs can also be used in this construction, unlike the cases presented above in (74-75).

(83) Misantla Totonac (Totonac-Tepehua)

47 The suffix-nahas morphotactic restrictions as it cannot co-occur with certain suffixes.

48 A similar phenomenon is found in Jacaltec (Mayan), where the preposition -et used to encode goals can be incorporated into the verb as a comitative applicative. In this construction, the secondary conjunct is not treated as a canonical object, but appears in topical position, see Craig (1977: 52-55) for more details.

49 With local participants, either the first or the second person is marked.

${ }^{50}$ In example (80), the marking of a third person subject is not obvious because it is encoded by means of a zero prefix or by the bare stem. 


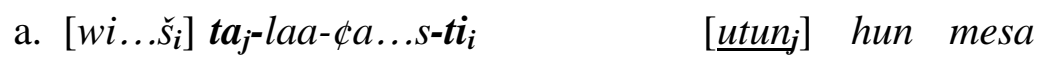

you(SG) SUB.PL-REC-lift[3OBJ]-2.PFV they DET table

'You lifted the table with them.' (MacKay 1999: 294)

(lit. 'You lifted the table with them, they lifted the table with you.')

b. $\left[k_{i t}\right] i_{i}-t_{j}-l a a-q a \ldots w a \ldots-y a a-n a \quad\left[u_{u t u m}\right]$

I 1SUB-SUB.PL-REC-talk-IMPFV-COMIT they

'I talked with them.' (MacKay 1999: 288)

(Lit. 'I talk with them, they talk with me.')

c. ta-laa-la ...qa ...n-kan-yaa-tat

SUB.PL-REC-see-REF-IMPFV-2SUB.PL

'You (pl) see each other.' (MacKay and Trechsel 2003: 283)

In this section, I have presented severe cases of split conjunction by integration where the conjunctional construction is not the extension of a counterpart comitative structure, and where the secondary conjunct works as an argument with the function of second subject. In functional terms, the secondary conjunct is a secondary topic, which can readily become an established topic for the following discourse. This is illustrated in (84). In (84a), the two participants are introduced by means of the split construction, while in (84b) they are both subject. However, the clause in (84c) has a singular third person subject, whose reference is interpreted to be the secondary conjunct.

(84) Highlands Otomi (Oto-Manguean; Otomi-Mazahua; Echegoyen and Voigtlander 2007: 15)
a.
$[a$
$d i-m-b Q n t^{\prime}=w i$
$\left.r a \quad n^{\prime} y o h Y\right]$$\quad\left[\begin{array}{ll}\text { raP } & \text { mbare }\end{array}{ }^{51}\right.$

[3.PRES.REAL]INFL-MIDDL-grasp=DU SG.3POSS fellow.parent DEF.SG SG man

'That man is fighting with his child's godfather.'

c. ngetho $i=K \ddot{i} t i$

because 3.PRES.REAL=get.drunk

'Because they are drunk.'

b. $\quad$ ëmme $\quad$ ra nexmate $={ }^{\prime} \mathrm{A}$
INT $\quad$ [3.PRES.REAL]SG provoker=3SG

'He (the child's godfather) is quite a provoker.'

Before concluding the paper, a few observations about the semantics of split conjunction by integration are in order to compare the distribution of the construction in different languages.

\subsection{The semantics of split by integration.}

In general conjunctional constructions involving splits commonly predicate a state of affairs involving human beings only. For example, the use of a split construction is not natural if one of the conjuncts is a human but the other is an animal. For such situations a

51 The noun mbare is a kinship term that names the role the godfather of a child has with that child's parents. 
comitative strategy is widely preferred. ${ }^{52}$ The same is true about all types of splits by integration, mild and severe.

Nevertheless, exceptions to this generalizationmay occur, especially when the animal is part of a listing including other human beings, as for example in (85) from Highlands Otomi. Notice that to produce the listing, the secondary conjunct is discontinuous; that is, the other members in the list appear after the primary conjunct.

(85) Highlands Otomi (VOS) (Oto-Manguean; Voigtlander and Echegoyen 2007: 240)

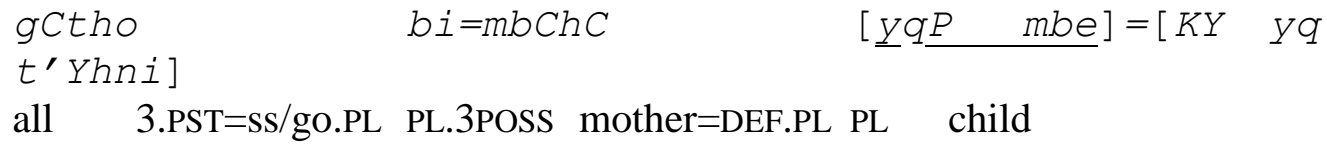

Only rarely does severe split conjunction involve an inanimate conjunct, and when it does, it almost always conveys a spatial ground, as shown in (86a). In other cases, the clause is used to describe the spatial disposition of an inanimate primary conjunct (86b). This does not happen in mild splits.

(86) a. San Ildefonso Otomi (Oto-Manguean; Otomi-Mazahua; Palancar 2009: 567)

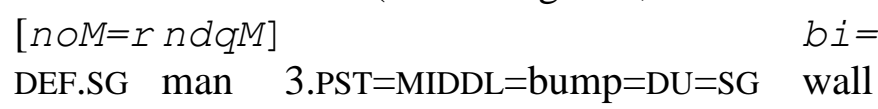

b. Misantla Totonac (Totonac-Tepehua; MacKay 1999: 299)

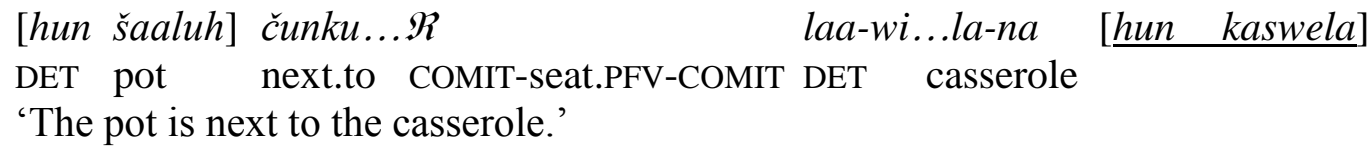

On the other hand, split conjunction by integration occupies an area in the semantic map of conjunctional semantics that lies in between the semantics conveyed by a coordinativestructure at one end and the comitative structure at the other. Because of this, an instance of a construction bearing this type of split conveys semantic nuances that are in principle translatable by using either structure in meta-languages like English. The choice of one construction over the other in the translation is at times random, but at times it also appears to respond to the feeling that the construction at hand is indeed used in a given language as semantically more equivalent to the nuances conveyed by the choice in the meta-language. If the comitative structure is used in the translation, the asymmetry in the topicality of the conjuncts is given prominence, while choosing a coordinative structure portrays the conjuncts with equal control. Constructions having splits by integration convey both these nuances at the same time.

52 As expected, in fable stories or other special circumstances with human-like animal participants, the use of the split construction is more natural. 
While constructions with severe split conjunction may serve to convey typical comitative notions, such as actions or motion events that involve human participants acting together, some languages may take it further to the coordinative end of the spectrum and use it to convey stative situations which are only possibly encoded by means of typical coordination. This is illustrated in Passamaquoddy in (87), where the state of affairs described is predicated of both participants independently. In other words, the state of affairs does not happen only once, and certainly the participants do not have to be together for the situation to be true. ${ }^{53}$

(87) Passamaquoddy (Algic, Algonquian; Bruening 2005: 17)

a. toqite [Mali] kisi-cipqahsin-uk [Piyel-ol]

both Mary PRF-have.nightmares-3PL Piyel-OBV

'Both Mary and Piyel had nightmares.'

b. [Susehp] apolahsatpih-ik [Piyel-ol]

Susehp be.bald-3PL Piyel-OBV

'Susehp and Piyel are bald.'

In contrast to Algonquian, the Otomi-Mazahua languages represent the opposite case. Severe split conjunction in such languages cannot be used apart from prototypical instances of accompaniment. In other words, when both participants act as actors, not as undergoers, like in (88). For such situations, a standard coordinative structure would instead be used.

(88) San Ildefonso Otomi (Oto-Manguean; Otomi-Mazahua; Palancar 2009: 562)
a. $*(n O M=K O P)$
$b i=d U=w Z P[=\underline{r} \quad$ KindO $]$
DEF.SG=3SG 3.PST=SS/die=DU=SG brother.of.woman
Intended reading: 'She and her brother died.'

b. $*(n O M=K O P)$

$b i=\mathbf{d C n g}=w Z P[=\underline{r}$

PePdro]

DEF.SG $=3$ SG 3.PST=SS/fall.from.height.AS=DU=SG Peter

Intended reading: 'He and Pedro fell down.'

\section{Concluding remarks: The whole picture.}

In this paper, I first revisited well-established knowledge about the common strategies used cross-linguistically to conjoin noun phrases, restricting myself to cases where the conjuncts rank high in the animacy hierarchy and the resulting conjoined NP functions as subject. Given the inherent asymmetry of conjunction, I distinguished the conjuncts as primary and secondary according to their prominence both for the purpose of syntax and information structure.

In $\S 3$, I presented an overview of constructions involving noun phrase conjunction which bear some type of a split in the phrasal continuity of the conjuncts while the verb

53 Notice the use of the emphatic coordinator toqite 'both' in (87a), proper of coordinative structures. 
shows resolved agreement with both conjuncts as a way to portray them with an equal rank as actors in the event. I have proposed that the splits are functionally motivated by a play of prominence of the conjuncts involved. In this regard, I have suggested that there are three main types of splits, i.e., splits by elision, by extraction and by integration.

In splits by elision, the conjuncts form a constituent, but their phrasal contiguity is disrupted because the primary conjunct is elided because of its topicality. As a consequence of this, the secondary conjunct is the only remaining element of the conjoined phrase on surface structure. In splits by extraction, the primary conjunct is given more prominence by being extracted or moved to a topical position, resulting in a surface structure where the two conjuncts are treated as two different constituents. Finally, in splits by integration, there is an upgrading of the secondary conjunct obtained by encoding it as a core participant of the action of the verb through resolved agreement. The conjuncts in splits by integration also appear in different positions in the clause. There are two subtypes of splits by integration. Those split constructions which are clearly based on a comitative structure existing in the language are treated as mild instances, but there are other, even rarer apparently, which function as fully independent constructs, where the NP encoding the secondary conjunct is treated as an argument of the verb.

Split conjunction involves all types of conjunctional structures but to different degrees. Inclusory and summative conjunction commonly undergo splits by elision and by extraction. Splits by elision are also found in coordinative structures, but only rarely, as presented in $\$ 3.1 .1$, while splits by extraction are not found in coordination except in nonconfigurational languages. In contrasts, splits by integration involve comitative structures at least for the mild subtype, and thus the relator involved is always a comitative one. Only in severe cases of split conjunction by integration, as found ina number of American Indian languages, such as Eastern Algonquian, Otomi-Mazahua and Misantla Totonac, the second conjunct is an NP not linked by any coordinator. In such cases, following Bruening's (2005) account, the second conjunct could be treated as a second subject.

Constructions featuring splits by integration may also involve splits by elision responding to pressures of information structure. This interaction is mainly allowed because a split by elision is more superficial in the syntax, as it involves the surface effacing of the primary conjunct, more rarely the secondary one. In this regard, in languages bearing these splits it is relatively common to find surface manifestations of the kind in (89).

(89) a. $\quad \mathrm{V}+\mathrm{DU} / \mathrm{PL}\left[(\mathrm{COMIT}) \mathrm{NP}_{2}\right]$

b. $\quad \mathrm{V}+\mathrm{DU} / \mathrm{PL}[\ldots$ (\&COMIT $\left.) \mathrm{NP}_{2}\right]$

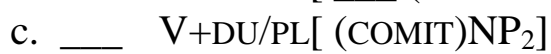

A structure like (89a) illustrates a split by elision of the primary conjunct, but the underlying structure is only revealed when the primary conjunct is restored, resulting in contiguous conjunction (inclusory or coordinative) as in (89b) or of a structure featuring split by integration as in (89c). ${ }^{54}$ The latter case is illustrated by K'ichee' in (90) where example (90b) instantiates the situation in (89a) where the primary conjunct has been elided for being the established topic. The restoration of the primary conjunct is given in $\left(90 b^{\prime}\right)$ and follows the form of (89c).

(90) K'ichee' (VOS) (Mayan; Telma Can, p.c.)

$$
\begin{array}{lllll}
\text { a. } x \text { - } \emptyset \text {-'e } & {[\boldsymbol{l e}} & \boldsymbol{a c h i}] & p a & k^{\prime} a y b^{\prime} a l \\
\text { COMPL-3ABS-go } & \text { DET man } & \text { P.LOC market }
\end{array}
$$

54 But notice the Nêlêmwa example in (35) above. 
'The man went to the market.'

b. choqe' $x$-ee-chaku-n $\quad\left[\underline{r-u k} k^{\prime} \quad \underline{l e} \quad n u-x b^{\prime}\right.$ aal $]$ and COMPL-3PL.ABS-work-ANTIP 3POSS-and/with DET 1POSS-brother 'And worked with my brother.'
b'. choqe' [le achi $]$ x-ee-chaku-n
$\left[\underline{r}-u k{ }^{\prime}\right.$
le nu-xb'aal]
and DET man COMPL-3PL.ABS-work-ANTIP 3POSS-and/with DET 1POSS-brother
'And the man worked with my brother.'

Before finishing the paper, it is worth mentioning two other ways in which a conjunctional construction can undergo a split. These are illustrated in Nakanai, an Oceanic language in (91), and may involve the extraction of the secondary conjunct to the right periphery of the clause as in (91a) or the extraction of both conjuncts independently to the external position of discourse topic as shown in (91b), where a resumptive plural pronoun indexes both conjuncts as subject. The structure in (91b) can be further contrasted with the one in (91c), which illustrates the more canonical extraction of the whole (asyndetically) conjoined NP.

(91) Nakanai (Austronesian, Oceanic; Johnston 1980)

a. $[e$ hatavile $]$ o_io po-pou, $[\underline{\text { la }}$ valalua $]$

NM women at.there RED-sit NM men

'The women are there waiting, and the men.' (p. 243 apud Bril in press: 244)

$\begin{array}{clll}\text { b. }[\boldsymbol{e} \text { hatavile }], & {[\underline{\text { la valalua }}]} & \text { egite o_io po-pou } \\ \text { NM women } & \text { NM men } & \text { 3PL at.there RED-sit }\end{array}$

'The women and the men are there waiting.' (p. 243 apud Bril in press: 244)

c. $[$ e Marisa e latu-la $]$, egira goata $e$ Malalia

NM Marisa NM child-3POSS 2DU go.up NM Malalia

'Marisa and her child, they've gone up to Malalia.' (p. 185 apud Bril in press: 214)

Splits in noun phrase conjunction are intriguing deviations from the canonical ideal of the symmetry of coordination structures, especially those involving coordinative structures, and deserve our attention. They are not common in Europe, but across the world's languages, particularly in some language groups, they are resilient structures. As the achievements of the field of linguistic typology walk hand in hand with the slow but extremely fruitful accomplishments in descriptive linguistics, the present study humbly hopes to serve as a map and inspire linguists to keep digging for more treasures in the deep sands of conjunctional strategies. Surprises are bound to await us.

Correspondence address:SeDyL (UMR8202) Centre National de la Recherche Scientifique (CNRS), 7 rue Guy Moquet, Bat. D, 94801 Villejuif Cedex, France.Surrey Morphology Group, Faculty of Arts and Human Sciences, University of Surrey, Guildford, Surrey GU2 7XH, Great Britain; e-mail: epalancar@ hotmail.com

Acknowledgements:This paper was written under the auspices of the ESRC/AHRC project RES-062-233126“Endangered Complexity: Inflectional classes in Oto-Manguean languages". I heartily thank Greville G. Corbett and Isabelle Bril for their invaluable comments on an earlier draft of this paper. I presented a version of the paper as a talk at the Linguistics Department of the Karl-Franz University of Graz on June 9 2011, and I am grateful for all the comments received, but I want to especially thank Bernhard Hurch for his cordial invitation to Graz, which came as a blessing to me in very difficult times. I also want to thank Judith Aissen, Selene Hernández, Rosemary Beam and Maris Camilleri for their wonderful help with Tzotzil, Santa Ana Otomi, Southern Zapotec and Maltese, respectively. I am indebted to Telma Can for her patience, 
generosity and support with the K'iche' data.Jean-Léo Léonard and Gilles Polian confirmed my humble intuitions about resolved agreementin French for note 26; Claudine Chamoreau provided me with just the right references. My thanks as well to Roberto Zavala with whom I share the passion for this constructional labyrinth in the Mesoamerican linguistic landscape.Similarly, I am most grateful to the three anonymous referees of the paper for their many comments and suggestions, especially to the first referee, whose rather insightful review inspired me to make a number of very important changes in both the presentation and the analysis which contributed substantially to the improvement of the paper. Finally, I also want to thank Penny Everson for proof-reading the English in the text. All errors and deficiencies remain my responsibility. 
Abbreviations: A class A of pronominal indexes, ABS absolutive,ACC accusative,ACT.FOC actorfocus,ANIM animate,ANPH anaphoric,ANT anterior,ANTIP antipassive,ART article,AS adjusted stem,ASS associative,AUX auxiliar,BS bound shape,BAS basic cross-referencing,CLF classifier,COMIT comitative,COMPL completive,CONJTV conjunctive inflection,CONJ conjunction,COP copula,DEF definite,DAT dative,DEM demonstrative,DET determiner,DIR directional/direct,DIM diminutive,DU dual,DUB dubitative,ENC phrase final enclitic,ERG ergative,EXCL exclusive,FACT factitive,FS free shape,F feminine,FOC focus, FR free pronoun,FUT future, HAB habitual,HUM human,IMPS impersonal,IMPF imperfect,IMPFV imperfective,INCH inchoative,INCL inclusive,INCOMPL incompletive, IND indicative,INDP independent, INFL inflectional marker,INFR inferred,INT intensive,IRR irrealis,LK linker,LOC locative,LOC.P locative preposition,M masculine,MIDDL middle,NARR.FOC narrative focus, NEG negative, $\mathrm{NF}$ nonfeminine,NM nominal marker,NOM nominative,NON.FUT non-future, OBJ object,OBL oblique, OBV obviative,PART participle,PARTCL particle,PFV perfective,POT potential,PL plural,POSS possessive,POSSD possessed,PRES present,PROG progressive,PRF perfect,PST past,PURP purposive,REL relative,REAL realis,REC reciprocal,RED reduplication,REFL reflexive,REM remote,REP reportative, SG singular,SS secondary stem,SUB subject,SUBJ subjunctive,TA tense/aspect,TOP topic,TRANSLOC translocative, VT versatile tense.

\section{References}

Abdoulaye, Mahamane L. 2004.Comitative, coordinating, and inclusory constructions in Hausa. In Haspelmath 2004a (ed.), 165-197.

Ahenakew, Freda and H. C. Wolfart (ed.) 1992.Kõhkominawak otãcimowiniwãwa - Our grandmothers' lives as told in their own words. Fifth House.

Aikhenvald, Alexandra Y. 2003. A Grammar of Tariana. Oxford: Oxford University Press.

- 2008. The Manambu language of East Sepik, Papua New Guinea. Oxford: Oxford University Press.

Aissen, Judith L. 1989. Agreement controllers and Tzotzil comitatives.Language65(3).518-36.

Allan, Keith. 1987. Hierarchies and the choice of left conjuncts (with particular attention to English). Journal of Linguistics 23(1).51-77.

Amfo, Nana Aba Appiah. 2010. Noun phrase conjunction in Akan: The grammaticalization path. Pragmatics 20(1).27-41.

Austin, Peter and Joan Bresnan. 1996. Non-configurationality in Australian Aboriginal languages. Natural Language and Linguistic Theory 14(2).215-268.

Beam, Rosemary. 2006. A Zapotec contribution towards the typology of inclusory constructions. Paper presented at the Annual Meeting of the Society for the Study of the Indigenous Languages of the Americas.Albuquerque, NM, 5-8 January.

- 2010. A Zapotec contribution towards the typology of inclusory constructions.Revised MS.

Beck, David. 2004. A grammatical sketch of Upper Necaxa Totonac. LINCOM: Europa.

Benmamoun, Elabbas; Bhatia,Archna and Polinsky, Maria. 2009. Closest conjunct agreement in head final languages. Linguistic Variation Yearbook9.67-88.

Bhat, D. N. S. 2004. Conjunction and personal pronouns. In Haspelmath 2004a (ed.),89108.

Black, Cheryl A. 2000. Quiegolani Zapotec Syntax: A Principles and Parameters account. Arlington, Texas: SIL International and the University of Texas at Arlington.

Blake, Barry J. 2001. The Noun Phrase in Australian Languages. InJane Simpson, David Nash, Mary Laughren, Peter Austin and Barry Lather (eds.), Forty years on: Ken Hale and Australian languages,415-425. Canberra: Pacific Linguistics. 
Bogdanov, V. N. 1968. Osobyl slučaj dialektnogo soglasovanija skazuemogo s podležaščim po smyslu i kategorija predstavitel'nosti.Naučnye doklady vysšej školy: filologičeskie nauki 4. 68-75.

Borsley, Robert D. 2005. Against ConjP, Lingua 115, 461-482.

Bresnan, Joan W., 2000. Lexical-Functional Syntax. Blackwell, Oxford.

Bril, Isabelle. 2004. Coordination Strategies and Inclusory Constructions in New Caledonian and other Oceanic Languages. InHaspelmath 2004a (ed.),499-533.

- 2010. Coordination inclusive et comitative dans les langues oceaniennes. In Franck Floricic (ed.), Essais de typologie et de linguistique générale: Mélanges offerts à Denis Creissels,361-382.Paris: ENS Editions.

- 2011. 'And' and 'with' conjunctive strategies in some Austronesian languages: Syntax, semantics, pragmatics. Special Issue on Coordination and Comitativity in Austronesian Languages.Language and linguistics12(1).239-272. Taipei: Academia Sinica.

- In press. Noun-phrase conjunction in Austronesian languages: additive. Inclusory and comitative strategies. In Claire Moyse-Faurie and Joachim Sabel (eds.), Topics in Oceanic Morphosyntax,211-263. Berlin: Mouton de Gruyter.

Brown, Cecil H., David Beck, Grzegorz Kondrak, James K. Watters and Søren Wichmann. 2011. Totozoquean. International Journal of American Linguistics 77(3).323-372.

Bruening, Benjamin. 2003. Split coordination and successive-cyclic movement in Passamaquoddy. Paper presented at Western Conference on Linguistics of the Department of Linguistics at California State University. http://udel.edu/ bruening/ Downloads/WECOLHO4.pdf .

- 2004. Verbal Reciprocals and the Interpretation of Reciprocals.Invited paper at the Linguistics Department of the University of Chicago, (MS).

- 2005. Split coordination in Passamaquoddy, (MS). http://udel.edu/ bruening/Downloads/SplitCoord1.pdf.

Camacho, José. 1996. Comitative coordination in Spanish. In Claudia Parodi, Carlos Quicoli, Mario Saltarelli and María Luisa Zubizarreta (eds.), Aspects of Romance Linguistics: Selected papers from the Linguistics Symposium on Romance Linguistics XXIV,107-122. Washington, D.C.: Georgetown University Press.

- 2000. Structural restrictions on comitative coordination.Linguistic Inquiry 31(2).366-275.

Corbett, Greville C. 1983. Hierarchies, targets and controllers: agreement patterns in Slavic. London: Croom Helm Ltd.

- 1988. Agreement: A partial specification based on Slavonic data. In M. Barlow and C. A. Ferguson (eds.), Agreement in Natural Languages, [Typological Studies in Language 17], 23-54. Stanford: CSLI Publications.

- 1991. Gender. Cambridge: Cambridge University Press.

- 2000. Number. Cambridge: Cambridge University Press.

- 2006. Agreement. Cambridge: Cambridge University Press.

Corbett, Greville G. and Marianne Mithun. 1996. Associative forms in a typology ofnumber systems: evidence from Yup'ik. Journal of Linguistics32.1-17.

Craig, Colette Grinevald. 1977. The structure of Jacaltec. Austin, Texas: The University of Texas Press.

Dalrymple, Mary and R.M. Kaplan. 2000. Feature indeterminacy and feature resolution. Language 4, 759-798.

Daniel, Michael \& Edith Moravcsik. 2005. The associative plural. InMartin Haspelmath, Matthew S. Dryer, David Gil and Bernard Comrie (eds.), The World Atlas of Language Structures WALS, 150-153. Oxford: Oxford University Press. 
Dixon, R.M.W. 1977. A grammar of Yidi/. Cambridge: Cambridge University Press.

- 1988. A grammar of Boumaa Fijian. Chicago: Chicago University Press.

Echegoyen, Artemisa and Katherine Voigtlander.2007. Diccionario Yuhú: Otomí de la Sierra Madre Oriental (Estados de Hidalgo, Puebla y Veracruz, México). Preliminary version. [Vocabularies and Diccionaries Series]. Mexico City: Instituto Lingüístico de Verano.

Fabri, Ray 1993. Kongruenz und die Grammatik des Maltesischen [Linguistische Arbeiten 292]. Tübingen: Niemeyer.

Feldman, Anna. 2001. Comitative and plural pronoun constructions. Proceedings of the 17th Annual Meeting of the Israel Association of Theoretical Linguistics.MS. http://linguistics.huji.ac.il/IATL/17/Feldman.pdf.

Gaby, Alice. 2006. A Grammar of Kuuk Thaayorre. Ph.D. thesis, University of Melbourne, Melbourne, Australia.

Grevisse, Maurice and André Goose. 1993. Le bon usage. Liège: Duculot (13th edition)

Haiman, John. 1985a. Symmetry. In John Haiman (ed.), Iconicity in Syntax, [Typological Studies in Language 17],73-95. Amsterdam/Philadelphia: John Benjamins.

- 1985b. Natural Syntax. Cambridge: Cambridge University Press.

Hale, Ken. 1983. Warlpiri and the grammar of non-configurational languages. Natural Language and Linguistic Theory 1(1).5-47.

Haspelmath, Martin (ed.). 2004a. Coordinating Constructions. Amsterdam: John Benjamins.

- 2004b. Coordinating constructions: An overview. In Haspelmath 2004a (ed.),3-40.

- 2007. Coordination. In Timothy Shopen (ed.), Language typology and syntactic description, Vol. II: Complex constructions,1-51. Cambridge: Cambridge University Press.

Haviland, John B. 1979. Guugu Yimidhirr Sketch Grammar. In R. M. W. Dixon and B. Blake (eds.), Handbook of Australian Languages, Volume I,26-180. Amsterdam: John Benjamins.

Heath, Jeffrey. 2008. A grammar of Jamsay. Berlin: Mouton de Gruyter.

Hoffmann, Carl. 1963. A grammar of the Margi language. London: Oxford University Press.

Johannessen, Janne Bondi. 1996. Partial agreement and coordination. Linguistic Inquiry 27, 661-676.

- $\quad$ 1998. Coordination. Oxford: Oxford University Press.

Johnston, Raymond L. 1980. Nakanai of New Britain.The Grammar of an Oceanic language. Canberra: Pacific Linguistics B-70.

Kayne, R.S., 1994. The Antisymmetry of Syntax.MIT Press, Cambridge, MA.

Lastra, Yolanda. 1989. Otomí de San Andrés Cuexcontitlán, Estado de México. (Archivo de Lenguas Indígenas, no. 13). Mexico City: El Colegio de México.

Lichtenberk, Frantisek. 1983. A grammar of Manam[Oceanic Linguistics Special Publication18]. University of Hawaii Press.

- 2000. Inclusory pronominals.Oceanic Linguistics 39(1).1-32.

- 2008. A Grammar of Toqabaqita, Volume II.Berlin: Mouton de Gruyter.

López Nicolás, Óscar. 2009. Construcciones de doble objeto en el zapoteco de Zoochina. Unpublished MA dissertation, Centro de Investigaciones y Estudios Superiores en Antropología Social, Mexico.

MacKay, CarolynJ. 1999. A grammar of Misantla Totonac. Salt Lake City: The University of Utah Press.

MacKay, Carolyn J. and Frank R. Trechsel. 2003. Reciprocal /laa-/ in Totonacan. International Journal of American Linguistics 69(3).275-306. 
McNally, Louise. 1993. Comitative coordination: A case study in group formation, Natural Language \& Linguistic Theory, 11(2).347-379.

Mitchell, Lewis. 1921/1976. Mikcic ('Turtle'). Indian Township, Maine: Wabnaki Bilingual Education Program. Edited and updated version of text in J. D. Prince (1921), 'Passamaqquoddy Texts' Publications of the American Ethnological Society 10.

Moravcsik, Edith. 2003. A semantic analysis of associative plurals, Studies in Language 27.469-503.

Mosel, Ulrike. 1984. Tolai Syntax and its historical development.Canberra: Australian National University.

Palancar, Enrique L. 2009. Gramática y textos del hñöñhö: Otomí de San Ildefonso Tultepec, Volumen I: Gramática. Mexico City: Plaza y Valdés.

Pollard, Carl. and Ivan A. Sag. 1994. Head-Driven Phrase Structure Grammar. University of Chicago Press, Chicago.

Quicoli, A. Carlos (undated), Conjunction in Micmac. (Ms).

Quirk, Randolph, Sidney Greenbaum, Geoffrey Leech and Jan Svartvik. 1985. A Comprehensive Grammar of theEnglish Language. London: Longman.

Radford, A. 1993. Head-hunting: on the trail of the nominal janus. In Greville Corbett, Norman Fraser and Scott McGlashan (eds.), Heads in Grammatical Theory. Cambridge University Press, Cambridge.

Rice, Keren. 2000. Morpheme order and semantic scope: Word formation in the Athapaskan verb. Cambridge: Cambridge University Press.

Ross, John R. 1967. Constraints on variables in syntax. PhD dissertation, MIT [Published as: Infinite syntax! Norwood, NJ: Ablex 1986].

Sadler, Louisa and Nordlinger, Rachel. 2006. Apposition as coordination: Evidence from Australian languages. In Miriam Butt and Tracy Holloway King (eds.), Proceedings of the LFG06 Conference,437-454. CSLI Publications. http://cslipublications.stanford.edu/LFG/13/papers/lfg08nordlingersadler. pdf

Schwartz, Linda. 1985. Plural pronouns, coordination, and inclusion. In Nancy Stenson (ed.), Papers from the Tenth Minnesota Regional Conference on Language and Linguistics,152-84. Minneapolis: Department of Linguistics, University of Minnesota.

- 1988a. Asymmetric Feature Distribution in Pronominal 'Coordinations'.In M. Barlow and C. A. Ferguson (eds.), Agreement in Natural Languages, [Typological Studies in Language 17],237-50. Stanford: CSLI Publications.

- 1988b. Conditions for verb-coded coordination. In M. Hammond, E. Moravcsik, and J. Wirth (eds.), Studies in Syntactic Typology,53-73. Amsterdam/Philadelphia: John Benjamins.

Sharp, Janet. 2004. Nyangumarta: A Language of the Pilbara Region of Western Australia.Canberra: Pacific Linguistics.

Singer, Ruth J. 2001a. The Inclusory construction in Australian languages.Melbourne Papers in Linguistics and Applied Linguistics 1(2).81-96.

- 2001b. The inclusory construction in Australian languages.Unpublished Honours Thesis, Universityof Melbourne.

Smeets, Ineke. 2008. A grammar of Mapuche. Berlin: Mouton de Gruyter.

Smith, Marcus. 2003. A common structure for cross-linguistic coordination patterns. Proceedings of the Berkeley Linguistics Society 29.

Stassen, Leon. 2000. And-languages and With-languages. Linguistic Typology 4.1-54.

- 2001. Noun phrase coordination. In Martin Haspelmath, E. König, W. Oesterreicher and W. Raible (eds). Language Typology and Language Universals, Vol. 2,11051111.Berlin: Mouton de Gruyter. 
- 2003. Noun phrase conjunction. In Frans Plank (ed.), Noun phrase structure in thelanguages of Europe,761-817. Berlin: Mouton de Gruyter.

- 2011. Noun Phrase Conjunction. In Matthew S. Dryer and Martin Haspelmath, (eds.), The World Atlas of Language Structures Online. Munich: Max Planck Digital Library, feature 63A. http://wals.info/feature/63A.

Stolz, Thomas. 2001. To be with $\mathrm{X}$ is to have $\mathrm{X}$ : Comitatives. Instrumentals, locative and predicative possession.Linguistics 39(2).321-350.

Stolz, Thomas, Stroh Cornelia, and Aina Urdze. 2006. On comitatives and related categories: A typological study with special focus on the languages of Europe. Berlin: Mouton de Gruyter.

Vassilieva, Maria Borisovna. 2005.Associative and Pronominal Plurality. Unpublished $\mathrm{PhD}$ dissertation, Stony Brook University.

Voigtlander, Katherine and Echegoyen, Artemisa.1979. Luces contemporáneas del otomí: Gramática del otomí de la sierra. Mexico City: Instituto Lingüístico de Verano.

Wälchli, Bernhard. 2005.Co-Compounds and Natural Coordination. Oxford: Oxford University Press.

Zavala Maldonado, Roberto. 2000. Inversion and other topics in the grammar of Olutec (Mixean). Ph.D. thesis, University of Oregon at Eugene.

- Zavala Maldonado, Roberto. 2012.Instrumentos y comitativos en la familia mixezoque: Una exploración desde la diacronía y la tipología. Paper presented at the V Coloquio sobre Lenguas Otomangues y Vecinas (COLOV5). Oaxaca, 20-22April.

Zwart, Jan-Wouter. 2005. Some notes on coordination in head-final languages. InJenny Doetjes and Jeroen van de Weijer (eds.), Linguistics in The Netherlands,232-241. Amsterdam/Philadelphia: John Benjamins.

\section{Figures}

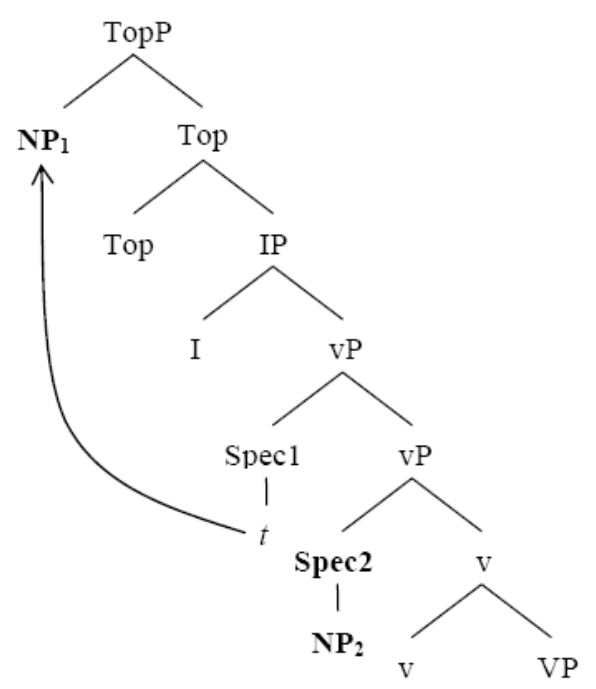

Figure 1 